\title{
Assessing the 2014 retroactive regulatory framework applied to the concentrating solar power systems in Spain
}

\author{
Jordi de la Hoz ${ }^{\text {a, d, }}$, Helena Martín ${ }^{\text {a, d }}$, Montserrat Montalà b, d, José Matas ${ }^{\text {a, d }}$, Ramon Guzman ${ }^{\text {c, e }}$ \\ a Department of Electrical Engineering, Universitat Politècnica de Catalunya (UPC), Escola d'Enginyeria de Barcelona Est (EEBE), C/ Eduard Maristany, 10-14, 08019 Barcelona, Spain

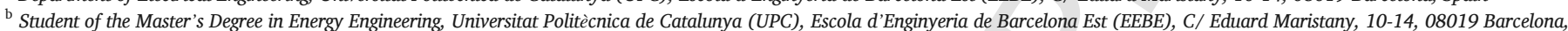 \\ Spain \\ ${ }^{c}$ Department of Automatic Control, Universitat Politècnica de Catalunya (UPC), Escola d'Enginyeria de Barcelona Est (EEBE), C/ Eduard Maristany, 10-14, 08019 Barcelona, Spain \\ ${ }^{\mathrm{d}}$ Universitat Politècnica de Catalunya (UPC), Escola d'Enginyeria de Barcelona Est (EEBE), C/ Eduard Maristany, 10-14, 08019 Barcelona, Spain \\ e Universitat Politècnica de Catalunya (UPC), Escola Politècnica Superior d'Enginyeria de Vilanova i la Geltrú (EPSEVG), Av. Víctor Balaguer, 1, 08800 Vilanova i la Geltrú, Spain
}

\section{ART ICLE INFO}

\section{Keywords:}

CSP

Renewable energy

Retroactivity

Market

Regulations

Spain

Feed in tariff (FIT)

\begin{abstract}
A B S T R A C T
The RD 413/2014 new economic and regulatory framework applied to the concentrating solar power plants (CSPP) in Spain has been here analysed and its new remuneration scheme has been formulated, becoming evident its high complexity and the great number of regulatory parameters involved. Next, a new model focused on determining its impact on the economic results of the existing CSPP has been proposed. Due to the complexity of the system, a methodology comprising a set of different stages of analysis has been developed. The new model has proven to be a useful tool to analyse the economic impact of the new regulatory scheme on the facilities and to identify its most influential regulatory parameters. One of the most representative facilities has been chosen as a case study to undertake the analysis. The results of the analysis, which have shown a substantial profitability reduction, have been consistent with the appreciations and data provided by the claimants of the last arbitral Award concerning the Kingdom of Spain and investors of CSPP in this country.
\end{abstract}

\begin{tabular}{|ll|}
\hline \multicolumn{2}{|l|}{ Nomenclature } \\
Acronyms \\
CPI $\quad$ Consumer Price Index \\
CSP $\quad$ Concentrating Solar Power \\
CSPP & Concentrating Solar Power Plants \\
ECT & Energy Charter Treaty \\
GCPVS & Grid Connected Photovoltaic Systems \\
ICSID & International Centre for Settlement of Investment Dis- \\
& putes \\
IRR & Internal Rate of Return \\
ISDS & Investor-State dispute settlement \\
MO & Ministerial Order \\
NPV & Net present value \\
PER 2005-2010 2005-2010 Spanish Renewable Energy Plan \\
RD & Royal Decree \\
RDL & Royal Decree-Law \\
\hline
\end{tabular}

\begin{tabular}{|c|c|}
\hline RES & renewable energy systems \\
\hline SCSPS & Spanish Concentrating Solar Power Sector \\
\hline SES & Spanish Electric System \\
\hline SR & Specific retribution \\
\hline \multicolumn{2}{|c|}{ Variables and parameters } \\
\hline$a$ & year in which a CSPP obtained the operating permit \\
\hline$a_{t}$ & $\begin{array}{l}\text { year in which a CSPP of type } t \text { obtained the operating } \\
\text { permit }\end{array}$ \\
\hline$C_{j, a}$ & $\begin{array}{l}\text { coefficient representing the investment cost of a CSPP } \\
\text { obtaining the operating permit in the year } a \text { that cannot } \\
\text { be recovered with the market revenue within } j\end{array}$ \\
\hline $\operatorname{Cexp}_{i}$ & $\begin{array}{l}\text { standard operating cost per unit of installed power for a } \\
\text { year } i \text { under the RD } 661 / 2007[€ / M W]\end{array}$ \\
\hline$C \operatorname{expf} f_{i}$ & $\begin{array}{l}\text { standard operating cost per unit of installed power } \\
\text { within the year } i \text { under the RD } 413 / 2014[€ / M W]\end{array}$ \\
\hline Cost $_{i}$ & cost in the year $i$ of the SCSPS $[€]$ \\
\hline Cost $_{i, t}$ & cost in the year $i$ of a CSPP of type $t[€]$ \\
\hline
\end{tabular}

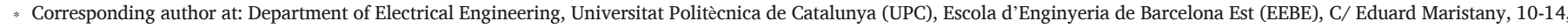
08019 Barcelona, Spain.

Email address: jordi.de.la.hoz@upc.edu (J.d.1. Hoz)
} 


\begin{tabular}{|c|c|}
\hline Cost $_{t}$ & cost of a CSPP of type $t$ over its lifetime $[€]$ \\
\hline$C P I_{i}$ & Consumer Price Index for the year $i$ \\
\hline$C P I_{i}{ }^{\prime}$ & $\begin{array}{l}C P I_{i} \text { at constant tax excluding unprocessed food and en- } \\
\text { ergy products }\end{array}$ \\
\hline \multicolumn{2}{|c|}{ Cumulative Cost cost of the SCSPS over their lifetime $[€]$} \\
\hline$C_{-} \operatorname{Eexpf}_{i} \mathrm{~s}$ & $\begin{array}{l}\text { standard operating cost per unit of generated energy in } \\
\text { the year } i \text { under the RD } 413 / 2014[€ / \mathrm{MWh}]\end{array}$ \\
\hline $\begin{array}{rl}C_{-} E e x p \_e i & \mathrm{~s} \\
\mathrm{t}\end{array}$ & $\begin{array}{l}\text { standard operating cost per unit of generated energy in } \\
\text { the year } i \text { under the RD } 661 / 2007 \text { [ } € / \mathrm{MWh} \text { ] }\end{array}$ \\
\hline C_Eexp_reali & $\begin{array}{l}l i \text { actual operating cost per unit of generated energy in } \\
\text { the year } i \text { under any regulatory framework }[€ / \mathrm{MWh}]\end{array}$ \\
\hline C_Eexp_stdi & $\begin{array}{l}\text { standard operating cost per unit of generated energy } \\
\text { in the year } i \text { under any regulatory framework } \\
{[€ / \mathrm{MWh}]}\end{array}$ \\
\hline & $\begin{array}{l}\text { weighting factor reducing } S R_{-} \text {Revenue }_{i} \text { according to } \\
\text { Nh_inst }_{i}\end{array}$ \\
\hline \multicolumn{2}{|c|}{ Discount_Rate rate of discount for the profitability analysis } \\
\hline & total energy generated within the year $i[\mathrm{MWh}]$ \\
\hline & $\begin{array}{l}\text { total energy generated within the year } i \text { by the CSPP of } \\
\text { type } t \text { [MWh] }\end{array}$ \\
\hline$E_{-} \max _{i}$ & $\begin{array}{l}\text { maximum value of } E_{i} \text { eligible for perceiving the } R o_{i} \\
\text { [MWh] }\end{array}$ \\
\hline Equity & value of the equity \\
\hline$F I T_{i, t}$ & $\begin{array}{l}\text { feed-in tariff in the year } i \text { for a type facility } t \\
\text { RD } 661 / 2007 \text { [€/MWh] }\end{array}$ \\
\hline \multicolumn{2}{|c|}{$F_{-} O M C_{a+1}$ fixed operating cost within the year $a+1$} \\
\hline & $\begin{array}{l}\text { standard income per unit of installed power } \\
\text { under the RD } 661 / 2007[€ / \mathrm{MW}]\end{array}$ \\
\hline $\operatorname{Ingf}_{i}$ & $\begin{array}{l}\text { standard operating income per unit of install } \\
\text { within the year i under the RD } 413 / 2014[€ / \mathrm{N}\end{array}$ \\
\hline Int_Rate $\mathrm{v}$ & value of the loan fixed interest rate \\
\hline Inv_Cost il & investment cost $[€]$ \\
\hline $\operatorname{In} v_{-} R_{i}$ & remuneration for the investment in the year $i[€]$ \\
\hline & three-year half-period \\
\hline & capital recovery factor \\
\hline & yearly degradation rate $[\%]$ \\
\hline & reasonable profitability \\
\hline \multicolumn{2}{|c|}{$\begin{array}{l}L I 1_{i, j}, L I 2_{i, j} \text { lower limits for the calculation of } \operatorname{Vajdm}_{i, j} \\
L S 1_{i, j,} L S 2_{i, j} \text { upper limits for the calculation of } \operatorname{Vajdm}_{i, j} \\
\text { Market_Revenue }_{i} \text { market revenue perceived in the year } i[€]\end{array}$} \\
\hline nd & number of years for the depreciation of the asset [years] \\
\hline$N h_{i, j}$ & $\begin{array}{l}\text { standard equivalent operating hours within the year } i \text { of } \\
j \text { under the RD } 413 / 2014[\mathrm{~h}]\end{array}$ \\
\hline$N h_{i, t}$ & $\begin{array}{l}\text { standard equivalent operating hours within the year } i \text { of } \\
\text { type facility } t[\mathrm{~h}]\end{array}$ \\
\hline Nh_ei & $\begin{array}{l}\text { standard equivalent operating hours within the year } i \\
\text { under the RD } 661 / 2007[\mathrm{~h}]\end{array}$ \\
\hline Nh_ei,t & $\begin{array}{l}\text { standard equivalent operating hours within the year } i \text { of } \\
\text { type facility } t \text { under the RD } 661 / 2007[\mathrm{~h}]\end{array}$ \\
\hline Nh_eohi,t s & $\begin{array}{l}\text { standard equivalent operating hours within the year } i \text { of } \\
\text { type facility } t \text { under any regulatory framework [h] }\end{array}$ \\
\hline Nh_inst ${ }_{i}$ & $\begin{array}{l}\text { actual equivalent operating hours within the year } i \text { un- } \\
\text { der any regulatory framework }[\mathrm{h}]\end{array}$ \\
\hline \multicolumn{2}{|c|}{$N \underline{L}_{-}$inst $_{a+1}$ initial value of $N h_{-}$inst $_{i}$} \\
\hline \multicolumn{2}{|l|}{$N \underline{-}_{\max } \max _{(\mathrm{Ro} i}$} \\
\hline$N h \_\min _{i}$ & $\begin{array}{l}\text { minimum value of } N h_{-} \text {inst }_{i} \text { that does not entail a reduc- } \\
\text { tion of } S R \text { Revenue }_{i}[\mathrm{~h}]\end{array}$ \\
\hline $\begin{array}{l}\text { Nh_std } \\
\text { nyrd }\end{array}$ & $\begin{array}{l}\text { standard value of } N h_{i} \text { inst } t_{i}[\mathrm{~h}] \\
\text { number of years to replace the debt or term of the loan } \\
\text { [years] }\end{array}$ \\
\hline
\end{tabular}

$O p_{-} R_{i} \quad$ remuneration for the operation in the year $i[€]$

Operating Costi total operating cost for running the facility $[€]$

$p \quad$ first complete year of $j$

$P_{n} \quad$ rated power [MW]

$P_{t} \quad$ total capacity of the CSPP of type $t$ [MW]

$\mathrm{Pm}_{i} \quad$ average energy market price per unit of generated energy in the year $i[€ / \mathrm{MWh}]$

$\mathrm{Pmf}_{i} \quad$ future estimated average market price per unit of generated energy for the year $i[€ / \mathrm{MWh}]$

$P m_{-} e i \quad$ revenue per unit of generated energy in the year $i$ under the RD 661/2007 [€/MWh]

$P T_{-} I R R_{i} \quad$ pre-tax internal rate of return up to the year $i$

$r_{i} \quad$ curtailment for $\mathrm{CPI}_{i}$

Revenue $_{i}$ total revenue perceived in the year $i[€]$

$\operatorname{Rinv}_{j, a}$ remuneration for the investment per unit of installed power in a year $i$ within $j$ of a CSPP obtaining the operating permit in the year $a[€ / \mathrm{MW}]$

$R o_{i} \quad$ remuneration for the operation per unit of generated energy in the year $i[€ / \mathrm{MWh}]$

sm number of years of $j$

$S B_{j} \quad$ average yield during determined period of the 10-year Spanish bonds in the secondary market within $j$

$S R_{-}$Revenue $_{i}$ SR revenue perceived in the year $i[\epsilon]$

$t \quad$ type facility code

$t_{j} \quad$ per unit discount rate within $j$ corresponding to the rea-

sonable profitability

Tax_Rate rate of corporate tax

Tax_E tax on the produced energy [€/MWh]

$\operatorname{Tax}_{-} R$ tax on the retribution of the produced energy [\%]

$U f_{i} \quad$ threshold of Nh_inst $_{i}$ for perceiving SR_Revenue ${ }_{i}[\mathrm{~h}]$

$V a j d m_{i, j} \quad$ coefficient adjusting the deviations of $P m_{i}$ from $P m f_{i}$

$V_{a} \quad$ standard value of the initial CSPP investment per unit of installed power [€/MW]

$V N A_{j, a} \quad$ net value per unit of installed power in a year $i$ within $j$ of a CSPP obtaining the operating permit in the year $a$ [€/MW]

$V R_{j} \quad$ remaining number of years at the beginning of $j$ to the end of the facility $V U$ [years]

$V U$ regulatory lifetime [years]

$V_{-} O M C_{a+1}$ variable operating and maintaining cost within the year $a+1$

$\Delta C_{-} E_{\text {exp_std }}$ deviation between $C_{-}$Eexp_Real $_{i}$ and C_Eexp_std [€/MWh]

$\Delta P m f(\%)$ deviation between $P m_{i}$ and $P m f_{i}$.

$\Delta N h_{-} s t d_{i}$ deviation between $N h_{-} i n s t_{i}$ and $N h_{-} s t d_{i}[\mathrm{~h}]$

$\Delta t_{j} \quad$ differential added to $S B_{j}$ for determining $t_{j}$

$\Delta V I_{a} \quad$ deviation between Inv_Cost and $V I_{a}[€ / \mathrm{MW}]$

\section{Introduction}

The research on Concentrating Solar Power (CSP) has gained great momentum in the last years. The short survey in Table 1 illustrates how prolific this research has become. There, a representative sample of relevant studies constituting the state of the art of CSP has been classified into the main topics that have shaped the recent research. As a result, four different thematic areas (placed as the main rows of Table 1) have been identified, namely, "Regulatory Analysis", "Economic Analysis", "Sector Studies" and "Technical Analysis". In addition, some of the thematic areas have been split into different subsections in order to provide a greater level of detail. Also, the references have been organized into different columns according to the focus country or region. 
Table 1

Classification of the CSP state of the art into thematic areas and focus country/region. Source: self-elaboration.

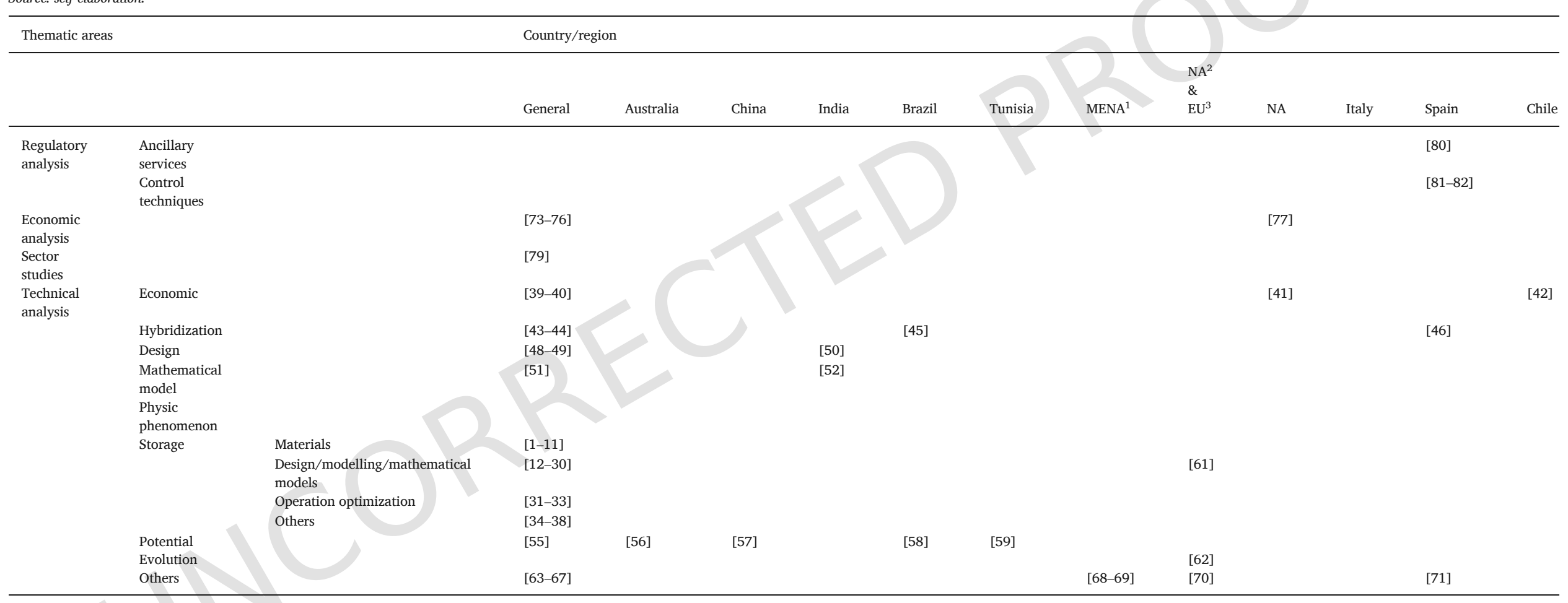

1 MENA (Middle-East and Nord Africa)

2 NA (Nord Africa).

3 EU (European Union). 
The research not specially addressed to any particular location was placed under the heading "General".

Clearly, it has been the category "Technical Analysis" [1-72] which has captured the greatest attention of the researchers and its subsection "Storage" should be praised as the most prolific one [1-38,61]. Although in a lesser amount, it is also possible to find some studies related to the economic performance of CSP, either combining economic and technical aspects or focusing the attention on purely economic considerations [73-79].

It is noticeable however the lack of studies addressed to analyse the regulatory frameworks applied to the CSPP, particularly in the case of leader countries such as Spain or the United States of America [80-82]. In this regard, the Spanish case only accounts for one article analysing in depth the regulatory framework responsible for its astonishing growth [81]. This is remarkable when compared with the attention received by the frameworks for the promotion of renewable energy systems (RES) in general [83-85] or with particular RES technologies such as wind systems or photovoltaic systems [86-99].

With $2300 \mathrm{MW}$, Spain is currently the first country in the world in terms of installed CSPP capacity, representing the $48.37 \%$ of the global capacity [100]. Consequently, the drastic reform of the regulatory framework for RES that Spain underwent in 2014 (Royal Decree (RD) 413/2014) has had a direct impact on nearly half of the CSP world installed capacity, with energy assets above $13,000 \mathrm{M} €$. Related to this, Spain was in 2015 and 2016 one of the most frequent respondent States in terms of investor-State dispute settlement (ISDS) [101-103], in part because of its 2014 regulatory reform for RES. Particularly, the Spanish CSP sector (SCSPS) has been forced to sue the Kingdom of Spain in the Spanish Courts and abroad. Also, some foreign investors, which invested in CSP in Spain under the former regulatory framework RD 661/2007, submitted a dispute to the International Centre for Settlement of Investment Disputes (ICSID) based on the Energy Charter Treaty (ECT) [104].

The results of this dispute and the analysis of the Spanish last regulatory reform for RES are of interest, not only because they concern near half of the global CSP installed capacity, but because these might provide to the potential CSP investors a clear prospective about future regulatory risks. Even more when near $45 \%$ of the worldwide CSP capacity (about $3969 \mathrm{MW}$ ) is under construction or in the development stage [105].

Despite the deep effects of the 2014 regulatory reform on the SCSPS and the last results of the ongoing juridical battle between the Kingdom of Spain and the local and foreign investors in CSP, to the authors' knowledge, there are no studies that have focused their attention on this subject. Following this gap, and in order to determine the economic impact of the Spanish new energy policy on CSP assets, this paper identifies the objectives of the new Spanish regulatory framework for CSPP RD 413/2014 and connects them with the cost that these systems have introduced to the Spanish Electric System (SES) under the previous regulatory framework RD 661/2007. To do so, this cost is first formulated and analysed, determining its evolution according to the existing SCSPS capacity and depending on several scenarios. Next, the 2014 Spanish regulatory framework RD 413/2014 applied on CSPP is introduced and described (Section 2). Then, as a novelty, a new physical, economic and regulatory model for CSPP according to the 2014 reform, which is able to replicate the main aspects of the economic reality of the CSPP in Spain, is formulated and justified (Section 3). In addition, the evaluation of the economic impact of these measures on the SCSPS are determined by analysing one of its most representative CSP facilities. The results are carefully assessed and discussed, as well as some of the most important remarks concerning the last arbitral Award related to the 2014 new regulatory reform on the SCSPS. The model and the undertaken analysis of the results have proved to have a clear and real application on the most spread CSP facilities in Spain, being this one of the main contributions to the state of the art (Section 4). Finally, all the factors deemed relevant for the SCSPS are duly systematized and conclusions are raised (Section 5).

\section{Objectives and working mechanism of the RD 413/2014 CSP regulatory reform}

\subsection{Setting the context}

In July 2013, the Royal Decree-Law (RDL) 9/2013 [106] was enacted to tackle the economic burden of the SES that was seriously affecting its financial stability. The former economic frameworks for RES stated by the RD 661/2007 [107] and RD 1578/2008 [108] were abolished and the foundations of the new retribution scheme were set. Consolidating this inflection point, the new law of the SES Law 24/2013 [109] of December 2013 established the new retribution scheme for the RES. The revenues of either the existing or the future RES would comprise two retribution concepts, i.e., the energy price negotiated in the day ahead market and a specific retribution (SR). The SR should guarantee the RES a reasonable profitability that they cannot get from the day ahead market energy price alone. For the case of the existing RES facilities, the structure and the values of the new economic scheme were developed by the RD 413/2014 [110] and the Ministerial Order (MO) IET 1045/2014 [111].

According to the Law 24/2013, the reason behind the SES financial instability was the disequilibrium between incomes and costs, which in 2013 resulted in a structural deficit around 26,000 M€. The lack of adaptability of the former retribution schemes for RES to the evolution of the economy or to the SES needs was pointed to as one of the causes of the financial instability. Reference was also made to the lack of results of the regulatory measures so far taken ${ }^{1}$ to contain the disequilibrium.

The case of the CSPP might perfectly exemplify the impact of the RES retribution on the SES cost. With a capacity objective of $500 \mathrm{MW}$ under the RD 661/2007, near $2300 \mathrm{MW}$ were finally developed. As a result, 50 CSPP were installed in Spain in 2013, exceeding the capacity goal by about $1800 \mathrm{MW}$.

The MO IET 1045/2014 classified the 50 existing CSPP according to their technology subtype and the year in which their operating permits were obtained $\left(a_{t}\right)$. As a result, 20 different groups of type facilities appeared and each one of these groups was identified by a consecutive type facility code $(t)$ ranging from IT to 00,601 to IT-00,620 (see Table 2 ). The number of CSPP included in each of the type facility codes can be seen in Fig. 1.

For each of the 20 different type facilities, the MO IET 1045/2014 also assigned initial values to the regulatory parameters defined in the RD 413/2014 related to the CSPP physical behaviour and economic remuneration. Some of these regulatory parameters have been used here to determine the cost of the SCSPS under the economic framework RD $661 / 2007$ prior to the 2014 reform. Specifically, these parameters refer to the standard equivalent operating hours within the year $i$ of a type facility $t$, either under the previous RD 661/2007 framework $\left(N h_{-} e_{i, t}\right)[\mathrm{h}]$ or under the new one RD 413/2014 $\left(N h_{i, t}\right)[\mathrm{h}]$.

As regards $N h_{i, t}$, from 2015 onwards it experiences a yearly linear decrease from the value assigned to $2014\left(N h_{2014, t}\right)^{2}$, as follows:

1 RDL 6/2009, RD 1565/2010, RD 1614/2010, RDL 14/2010, RDL 1/2012, RDL 29/ 2012, Law 5/2012 and RDL 2/2013 [81,99].

2 The sole exception is the IT-00,615, for which from 2017 onwards, $N h_{i, t}$ is yearly decreased from the value assigned to 2016. Nevertheless, this singular behaviour not covered by Eq. (1) is not relevant since any CSPP was finally included under this type facility code (see Fig. 1). 
Table 2

Type facility codes assigned to the SCSPP.

Source: self-elaboration based on [111].

\begin{tabular}{|c|c|c|}
\hline Tsubtype & $\begin{array}{l}\text { Year of } \\
\text { operating permit } \\
\text { award }(a)\end{array}$ & $\begin{array}{l}\text { Type } \\
\text { facility } \\
\text { code }(t)\end{array}$ \\
\hline \multirow{5}{*}{$\begin{array}{l}\text { Parabolic trough without storage or with } \\
\text { storage less than } 2 \mathrm{~h}(\mathrm{CCP})\end{array}$} & 2009 & IT-00601 \\
\hline & 2010 & IT-00602 \\
\hline & 2011 & IT-00603 \\
\hline & 2012 & IT-00604 \\
\hline & 2013 & IT-00605 \\
\hline \multirow{6}{*}{$\begin{array}{l}\text { Parabolic trough with storage, within } 5 \mathrm{~h} \\
\text { and } 8 \mathrm{~h}(\mathrm{CPA}>5 \mathrm{~h} \leq 8 \mathrm{~h})\end{array}$} & 2008 & IT-00606 \\
\hline & 2009 & IT-00607 \\
\hline & 2010 & IT-00608 \\
\hline & 2011 & IT-00609 \\
\hline & 2012 & IT-00610 \\
\hline & 2013 & IT-00611 \\
\hline \multirow{2}{*}{$\begin{array}{l}\text { Parabolic trough with storage greater } \\
\text { than } 8 \mathrm{~h}(\mathrm{CPA}>8 \mathrm{~h})\end{array}$} & 2012 & IT-00619 \\
\hline & 2013 & IT-00620 \\
\hline \multirow{2}{*}{$\begin{array}{l}\text { Saturated steam tower without storage or } \\
\text { with storage less than } 2 \mathrm{~h} \text { (TOV) }\end{array}$} & 2006 & IT-00612 \\
\hline & 2009 & IT-00613 \\
\hline \multirow{2}{*}{$\begin{array}{l}\text { Molten salt tower with storage greater } \\
\text { than } 12 \mathrm{~h} \text { (TOA) }\end{array}$} & 2011 & IT-00614 \\
\hline & 2015 & IT-00615 \\
\hline \multirow{2}{*}{$\begin{array}{l}\text { Fresnel without storage or with storage } \\
\text { less than } 2 \mathrm{~h} \text { (FRE) }\end{array}$} & 2009 & IT-00616 \\
\hline & 2012 & IT-00617 \\
\hline Hybrid type II (HIB) & 2012 & IT-00618 \\
\hline
\end{tabular}

$N h_{i, t}$

$=\left\{\begin{array}{cc}0 & a_{t} \geqslant i \vee i>a_{t}+40 \\ N h_{2014, t} \cdot\left[1-K_{R} \cdot(i-2014)\right] & 2014 \leqslant i \leqslant a_{t}+40\end{array}\right.$

where $K_{R}$ is a constant degradation rate of $0.2 \%$ and the lifetime of the CSPP has been assumed for the cost calculation purposes to be 40 years.

For each type facility $t$, its number of standard equivalent operating hours for any operation year $i\left(N h_{-} e o h_{i, t}\right)[\mathrm{h}]$ can be expressed as follows:

$$
N h_{-} e o h_{i, t}=N h_{-} e_{i, t}+N h_{i, t}
$$

being 2013 the only year where the different frameworks RD 661/2007 and RD 413/2014 coexisted and both $N h_{-} e_{i, t}$ and $N h_{i, t}$ take simultaneously non null values. ${ }^{3}$

The energy produced by the type facility $t$ within the year $i\left(E_{i, t}\right)$ [MWh] is calculated as:

3 Although issued in 2014, the RD 413/2014 and the regulatory parameters set by the MO IET $1045 / 2014$ apply since the entry into force of RDL $9 / 2013$ in July 2013, because it put the basis of the new remuneration scheme to come in 2014 .
$E_{i, t}=P_{t} \cdot N h_{-} e o h_{i, t}$

where $P_{t}[\mathrm{MW}]$ is the total capacity of the CSPP classified under a particular type facility code $t$.

The evolution of the installed power of the CSPP contrasts with the expected operative power of the CSPP within a year $i$, whose values were published in the 2005-2010 Spanish Renewable Energy Plan (PER 2005-2010) [112] and are reported in Table 3.

Also, under a simplified approach, ${ }^{4}$ the feed-in tariff scheme in a year $i\left(F I T_{i, t}\right)[€ / \mathrm{MWh}]$ of the RD 661/2007 can be expressed as:

$$
\begin{aligned}
& F I T_{i, t} \\
& =\left\{\begin{array}{cc}
F I T_{2007} & i=2007 \\
F I T_{i-1, t} \cdot\left(1+C P I_{i-1}-r_{i}\right) & 2008 \leqslant i<a_{t}+25 \\
F I T_{a_{t}+25} & i=a_{t}+25 \\
F I T_{i-1, t} \cdot\left(1+C P I_{i-1}-r_{i}\right) & i \leqslant a_{t}+40
\end{array}\right.
\end{aligned}
$$

where the values of $F_{T} T_{2007}$ and FIT $T_{a t+25}$ were set in the RD 661/2007 to $269,375 € / M W h$ and $215,498 € / M W h$, respectively, $C P I_{i-1}$ is the Consumer Price Index for the year $i-1$ and $r_{i}$ is a parameter intended to curtail the value of $C P I_{i-1}$. Until 2012, $r_{i}$ was set to 25 basis points and 50 basis points thereafter.

As a result, the cost $\left(\operatorname{Cost}_{i, t}\right)$ within a year $i$ for each type facility $t$ can be calculated as:

$\operatorname{Cost}_{i, t}=E_{i, t} \cdot F I T_{i, t}$

In turn, the annual cost (Cost $\left.t_{i}\right)$ to the SES in a year $i$ of all the SCSPS under the RD 661/2007 can be determined by:

Cost $_{i}=\sum_{t} \operatorname{Cost}_{i, t}$

In the same way, the cost of promotion of each type facility $t$ during its lifetime can be calculated as:

Cost $_{t}=\sum_{i} \operatorname{Cost}_{i, t}$

Finally, the cumulative cost of the entire SCSPS under the RD 661/ 2007 is:

Cumulative Cost $=\sum_{t} \sum_{i}$ Cost $_{i, t}$

For a constant inflation intermediate scenario $(C P I=3 \%)$, Fig. 2 shows in red columns the evolution of the SCSPS annual cost (Cost $\left.)_{i}\right)$ and in red solid line the evolution of the yearly cumulative cost (Cumulative Cost $_{i}$ ). For comparison purposes, Fig. 2 also shows in blue columns the expected annual cost (Exp_Cost $\left.t_{i}\right)$ and in blue solid line the expected yearly cumulative cost (Exp_Cumulative Cost $t_{i}$ ) if the CSPP deployment had occurred according to the PER 2005-2010 (see Table 3). The Cost and Exp_Cost $t_{i}$ are referenced to the left axis of Fig. 2, while Cumulative Cost $_{i}$ and Exp_Cumulative Cost ${ }_{i}$ are referred to the right axis. It is worth noting the sharp fall in the annual costs due to the FIT reduction after the first 25 years of operation of the CSPP.

As can be seen in Fig. 2, the final value of the cumulative cost of the SCSPS to the SES would have amounted to $75,376 \mathrm{M} €$ under the RD $661 / 2007$ framework, which was equivalent to $6 \%$ of the 2012 Spanish gross domestic product. On the other hand, the final value of the cumulative cost would have been 18,242 M€ for a CSPP deployment as envis-

4 Eq. (4) does not reflect none of the legislative changes subsequently applied to RD $661 / 2007$ 


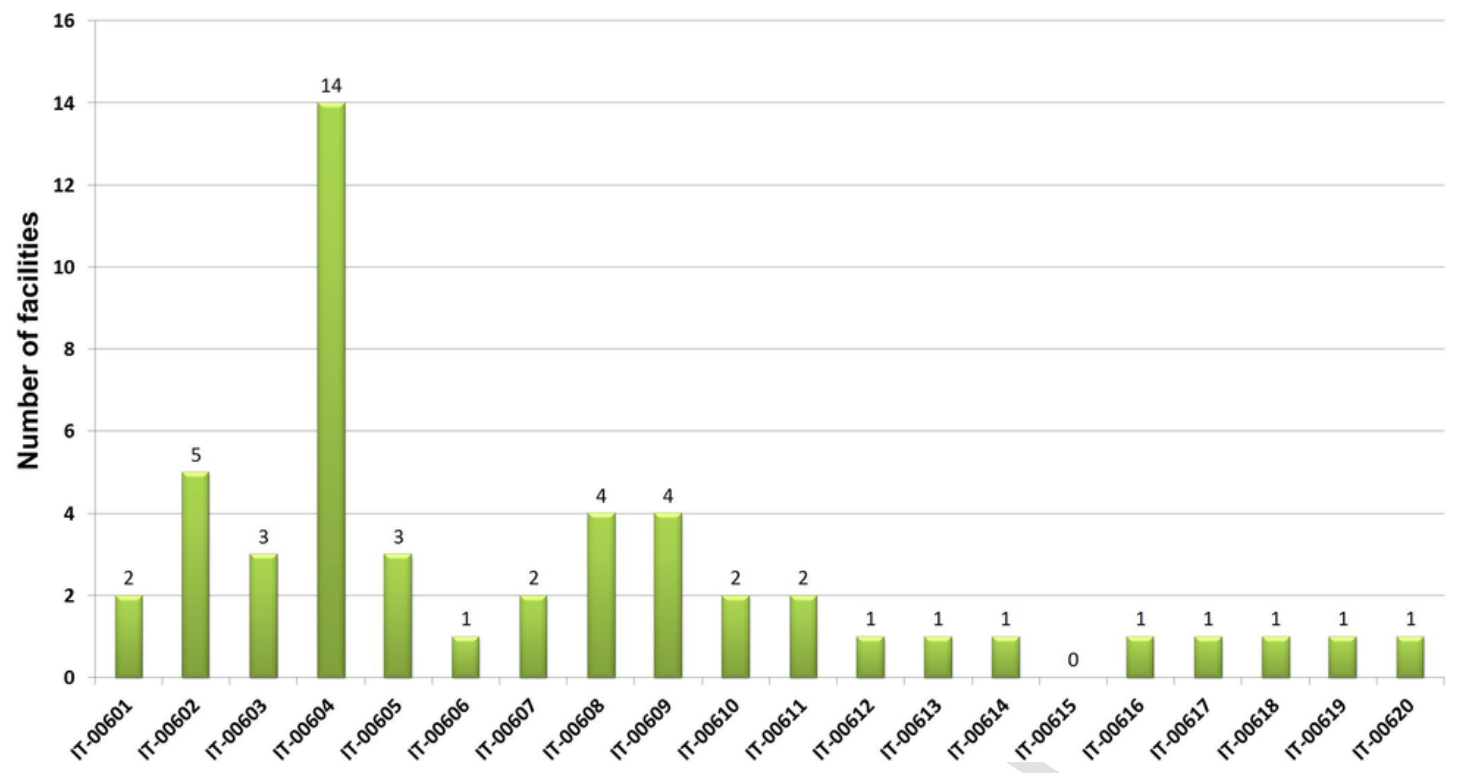

Fig. 1. Number of CSPP included in each type facility code. Source: self-elaboration based on [111].

Table 3

CSPP annual capacity deployment $\mathrm{P}_{\mathrm{i}}$ outlined in the PER 2005-2010.

Source: [112].

\begin{tabular}{|c|c|c|c|c|c|c|}
\hline Year (i) & 2006 & 2007 & 2008 & 2009 & 2010 & Total 2006-2010 \\
\hline$P_{i}[\mathrm{MW}]$ & 10 & 40 & 150 & 150 & 150 & 500 \\
\hline
\end{tabular}

$M €$

M€

3.000

80.000

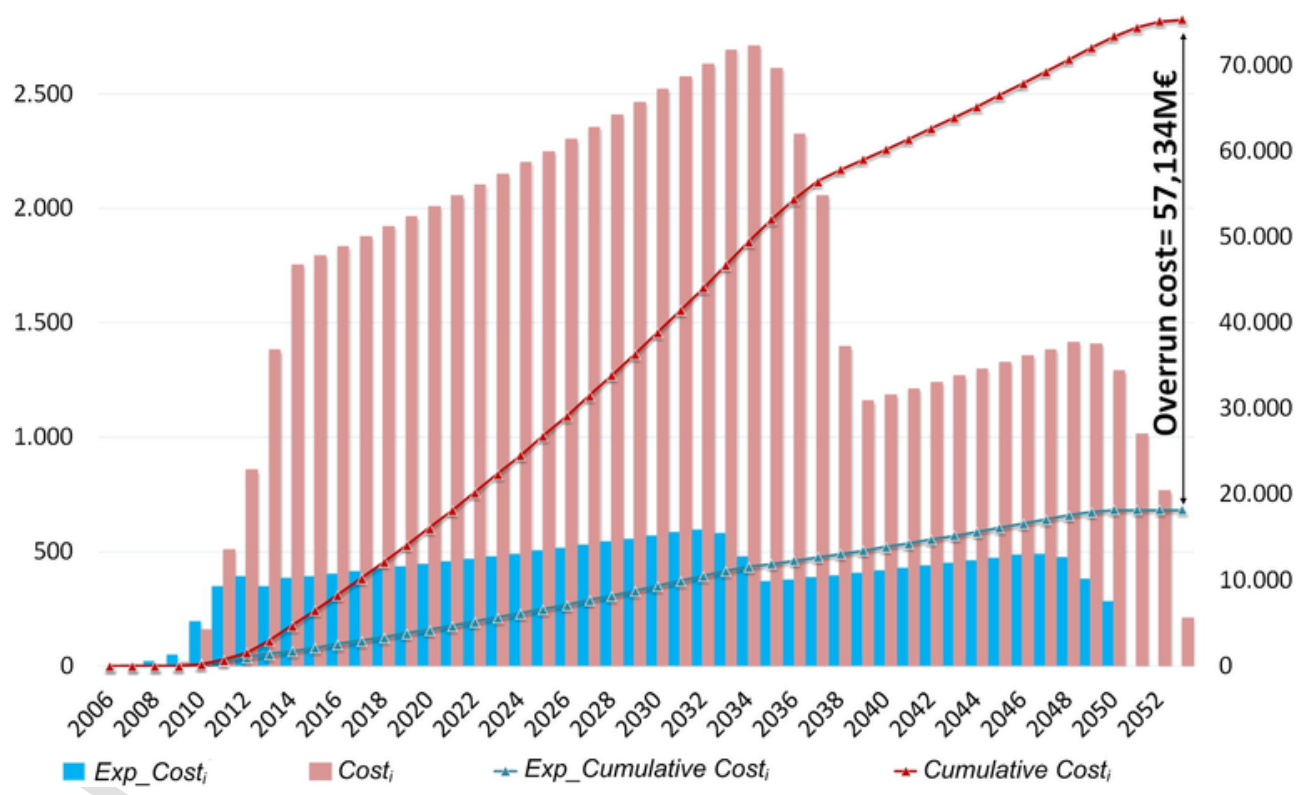

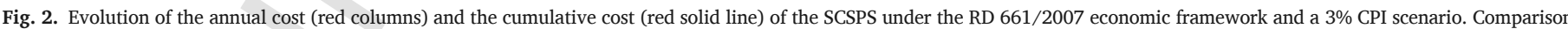

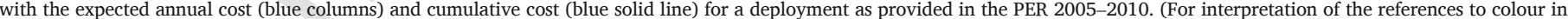
this figure legend, the reader is referred to the web version of this article.) Source: Self-elaboration.

aged in the PER 2005-2010. Consequently, the resulting overrun cost for the SES would have been 57,134M $€$.

The overrun cost of the CSP promotion, along with the corresponding to other RES technologies, impacts on the regulated costs of the
SES through the electricity tariff. This fact justifies the financial stability awareness stressed by the RDL $9 / 2013$ and the Law 24/2013. The RD $413 / 2014$ was the regulatory tool introduced to control the cost to the SES of the electricity from RES. 


\subsection{Describing the $R D 413 / 2014$ new regulatory framework applied to the CSPP}

In a previous work the authors provided a detailed mathematical model of the new RD 413/2014 economic and regulatory framework, in order to evaluate its impact on the income statement of the existing grid connected photovoltaic systems (GCPVS) in Spain [113]. The reproduction of this model is essential to analyse here its economic impact on the existing CSPP. Even more, the modifications that have been made on this model to adapt it to the specificities of the CSPP can barely be understood unless the model is again presented. Nevertheless, for the sake of brevity, the mathematical expressions will be here shown in compact form in Table 4 and referred as needed in the discussion. Also, graphical aids have been provided in order ease the understanding of the complex global mechanism of action of the RD 413/2014, which is in itself a new contribution.

Thus, Fig. 3 provides a conceptual approach to the working principle of the RD 413/2014. The input parameters are located in the coloured boxes at the left side of the graph, and the output of the model, i.e., the revenue of the CSPP, is placed at the upper right corner. Most of the parameters are of economic and finance nature with regulatory assigned values, which are placed into yellow-coloured boxes. The input parameters of economic type with values not regulatory set are put into grey-coloured boxes, while those concerning physical properties of the CSPP are placed into blue-coloured boxes.

The RD 413/2014 defined six-year regulatory periods, split into three-year half-periods $(j)$. All the parameters, but the regulatory lifetime $(V U)$ and the standard value of the initial CSPP investment per unit of installed power $\left(V I_{a}\right)$, can be updated at the end of either each regulatory period or half-period.

As can be seen in the upper right corner of Fig. 3, the total revenue perceived in a year $i$ by a CSPP (Revenue $)$ ) is the sum of the market revenue (Market_Revenue ${ }_{i}$ ) and the SR revenue (SR_Revenue ${ }_{i}$ ) (see Table 4, Eq. (9)). Fig. 3 evidences the different degree of complexity of the computation of both types of revenues. Thus, the Market_Revenue ${ }_{i}$ in the year $i$ is simply calculated as the total generated energy $\left(E_{i}\right)$ by the yearly average energy market price per unit of generated energy $\left(P m_{i}\right)$ (see Eq. (10)). Notice that $E_{i}$ is not directly an input variable, but rather it is obtained from the rated power of the $\operatorname{CSPP}\left(P_{n}\right)$ by the number of equivalent operating hours (Nh_inst $t_{i}$ ) (see Eq. (11)). Similar to that done in Eq. (1), it has been assumed that $N h_{-}$inst $_{i}$ follows a decreasing function of the input parameters yearly degradation rate $\left(K_{R}\right)^{5}$ of the CSPP and initial number of equivalent operating hours within the year $a+1$ $\left(N\right.$ inst $\left._{a+1}\right),{ }^{6}$ where $(a)$ is the year in which the operating permit is obtained (see Eq. (12)).

On the other hand, most of Fig. 3 is devoted to the calculation of the $S R_{-}$Revenue $_{i}$, which is perceived during the CSPP VU. ${ }^{7}$ The $S R \_R e v$ enue $_{i}$ in a year $i$ is the sum of the remuneration for the operation $\left(O p_{-} R_{i}\right)$ and the remuneration for the investment $\left(I n v_{-} R_{i}\right)$ by a weighting factor $d_{i}$ (see Eq. (13)), which reduces the $S R_{-}$Revenue $_{i}$ if $N h_{-}$inst $_{i}$ falls below a first threshold $\mathrm{Nh}_{-} \mathrm{min}_{i}$ or even cancels it if $\mathrm{Nh}_{-}$inst $_{i}$ does not reach a second lower threshold $U f_{i}$ (see Eq. (14)). The $O p_{-} R_{i}$ is calculated by multiplying $E_{i}$ by the remuneration for the operation per unit of generated energy in the year $i\left(R o_{i}\right)$. Nevertheless, a cap is put on $E_{i}$

5 Although the MO IET/1045/2014 regulatory set $K_{R}$ at a constant $0.2 \%$, its real value could be different.

6 It is considered that the facility has not any revenue, cost or energy production in the year $a$.

7 From then on, only the Market_Revenue ${ }_{i}$ will apply.
$\left(E_{-} \max _{i}\right.$ ) (see Eq. (15)), which is proportional to the maximum value of $N h_{-} i n s t_{i}$ eligible for perceiving the $R o_{i}$ within the year $i\left(N h_{-} \max _{(R o)}\right)$ (see Eq. (16)). In turn, the $R o_{i}$ is intended to compensate for the standard operating cost per unit of generated energy estimated for an efficient and well managed CSPP $\left(C_{-} \operatorname{Eexp}_{i}\right)$ that cannot be recovered with the estimated future market price per unit of generated energy $\left(P m f_{i}\right.$ ) (see eq. (17)). The value of $P m f_{i}$ for each year $i$ belonging to a subperiod $j$ will be determined as the arithmetic average of the yearly futures contracts prices negotiated in the Spanish regulated electricity futures market for the six months prior to the beginning of $j$.

On the other hand, as Fig. 3 shows, the term $I n v_{-} R_{i}$ within the $S R_{-} R e v-$ enue $e_{i}$ is the most complex to calculate. It is computed as $P_{n}$ by the remuneration for the investment per unit of installed power of a CSPP obtaining the operating permit in the year $a\left(\operatorname{Rin}_{j, a}\right)$, which remains constant within a regulatory half-period $j$ (see Eq. (18)).

In turn, $\operatorname{Rinv}_{j, a}$ is calculated as the product of three terms, namely, a per unit adjustment coefficient representing the investment cost that cannot be recovered with the market revenue $\left(C_{j, a}\right)$, the net value of the asset per unit of installed power $\left(V N A_{j, a}\right)$ and a capital recovery factor $\left(K_{j}\right)$. Nevertheless, $\operatorname{Rinv}_{j, a}$ can be cancelled before the end of the $V U$ if the profitability actually attained, calculated as a pre-tax internal rate of return (IRR) up to the year $i\left(P T_{-} I R R_{i}\right),{ }^{8}$ exceeds certain reasonable profitability level $\left(L_{R}\right)$ (see Eq. (19)).

Specifically, $C_{j, a}$ is computed as shown in Eqs. (20)-(22), where $p$ is the first complete year of $j, \operatorname{Ing} f_{i}$ and $\operatorname{Cexpf_{i}}$ are the future estimated operating income and cost per unit of installed power, respectively, and $N h_{i, j}$ is the number of standard equivalent operating hours within the year $i$ of $j$.

Likewise, $V N A_{j, a}$ is calculated as expressed in (23)-(27), where Ing and $\operatorname{Cexp}_{i}$ are the standard total income and operating cost, $P m_{-} e_{i}$ and $C_{-} E_{\text {exp_ }} e_{i}$ are the revenue from energy sales and the standard operating cost per unit of generated energy and $N_{-} e_{i}$ is the number of standard equivalent operating hours, respectively, all of them for a year $i<p$ under the previous regulatory framework $\mathrm{RD} 661 / 2007 . .^{9}$ Likewise, $s m$ is the number of years of $j$ and $V a j d m_{i, j-1}$ is a coefficient that adjusts the deviations of $P m_{i}$ from $P m f_{i}$ by checking $P m_{i}$ against two upper $\left(L S 1_{i, j}\right.$, $\left.L S 2_{i, j}\right)$ and two lower $\left(L I 1_{i, j}, L I 2_{i, j}\right)$ limits around $P m f_{i}$ and corrects $V N A_{j, a}$ in the following half-period $j$. Also, $t_{j}$ is the per unit discount rate that corresponds to the reasonable profitability before taxes within $j$, and is computed as the average yield during determined period of the 10-year Spanish bonds in the secondary market within $j\left(S B_{j}\right)$ plus a basis points differential $\left(\Delta t_{j}\right) .{ }^{10}$

Finally, $K_{j}$ is calculated in (28), where $V R_{j}$ is the remaining number of years at the beginning of $j$ to the end of the facility $V U$. By the effect of the capital recovery factor $K_{j}$, the product $C_{j, a} \cdot V N A_{j, a}$ is converted into a stream of annual payments Rinv $v_{j, a}$ of constant value throughout $j$.

In order to graphically illustrate the greater intricacy of the new $\mathrm{RD}$ 413/2014 framework (see Fig. 3) regarding the previous RD 661/2007, this latter has been conceptually depicted in Fig. 4. For a detailed explanation of the parameters and variables of the regulatory frameworks prior to RD 413/2014 the interested reader is addressed to [99].

\footnotetext{
8 As it is inferred from the RD 413/2014, the particular cash flow employed here for the $P T_{-} I R R_{i}$ calculation is purely the difference between the standard revenue and the standard operating cost.

9 As an exception, for $i=2013 I_{i} g_{i}$ must also include the term $S_{-}$Revenue $_{i}$, since the facilities perceived revenue from the RD 413/2014 framework as well.

10 For the existing CSPP and for $j=1, S B_{j}$ would be computed over the last 10 years prior to the entry into force of the RDL $9 / 2013$ and $\Delta t_{j}$ would be set to 300 basis points, resulting $t_{j}=7.395 \%$. For $j>1, S B_{j}$ would be computed over the last 24 months prior the first month of May previous to the beginning of $j$.
} 
Table 4

Mathematical model of the RD 413/2014 economic framework.

Source: Self-elaboration based on [110].

\begin{tabular}{|c|c|}
\hline Equation & Eq. Nr. \\
\hline Revenue_ $i=$ Market_Revenue_ $i+S R \_$Revenue_ $i$ & (9) \\
\hline Market_Revenue $_{i}=E_{i} P m_{i}$ & (10) \\
\hline$E_{i}=P_{n} \cdot N h{ }_{i n s t}$ & (11) \\
\hline Nh_inst $t_{i}=$ Nh_inst $_{a+1} \cdot\left[1-K_{R} \cdot(i-(a+1))\right], \quad i \geqslant a+1$ & (12) \\
\hline$S R_{-}$Revenue $_{i}=\left(O p_{-} R_{i}+I n v_{-} R_{i}\right) \cdot d_{i}$ & (13) \\
\hline$d_{i}=\left\{\begin{array}{cc}1 & N h \_i n s t_{i}>N h \_\min _{i} \\
N h \_ \text {inst } & \\
N t_{i}-U f_{i} & U f_{i} \leqslant N h \_i n s t_{i} \leqslant N h \_f_{i} \min _{i} \\
0 & U f_{i}>N h \_i n s t_{i}\end{array}\right.$ & (14) \\
\hline$O p \_R_{i}=\left\{\begin{array}{cc}E_{i} \cdot R o_{i}, & E_{i} \leqslant E \_\max _{i} \\
E_{-} \max _{i} \cdot R o_{i}, & E_{i}>E_{-} \max _{i}\end{array}\right.$ & (15) \\
\hline$E \_\max _{i}=P_{n} \cdot N h \_\max _{\left(R_{o}\right) i}$ & (16) \\
\hline $\begin{array}{l}R o_{i}=C_{-} \operatorname{Eexpf}_{i}-P m f_{i} \\
\operatorname{Inv} R_{i}=P_{r} \cdot \operatorname{Rinv}_{i}\end{array}$ & (17) \\
\hline $\begin{aligned} & R v_{-} R_{i}=P_{n} \operatorname{Rin} \operatorname{Rin}_{j, a} \\
& \operatorname{Rinv}_{j, a}=\left\{\begin{array}{cc}C_{j, a} \cdot V A_{j, a} \cdot K_{j}, & P T_{-} I I R_{i} \leqslant L_{R} \\
0, & P T_{-} I I R_{i}>L_{R}\end{array}\right.\end{aligned}$ & (18) \\
\hline 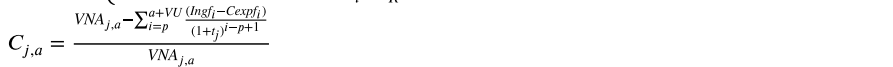 & (20) \\
\hline $\operatorname{Ingf}_{i}=\left(P m f_{i}+R o_{i}\right) \cdot N h_{i, j}$ & (21) \\
\hline $\begin{array}{l}\operatorname{Cexp}_{i}=C_{-} \operatorname{Eexp}_{i} N h_{i, j} \\
V N A_{j, a}\end{array}$ & $\begin{array}{l}(22) \\
(23)\end{array}$ \\
\hline$=\left\{\begin{array}{cc}V I_{a} \cdot\left(1+t_{j}\right)^{p-a-1}-\sum_{i=a+1}^{p-1}\left(\operatorname{Ing}_{i}-\operatorname{Cexp}_{i}\right) \cdot\left(1+t_{j}\right)^{p-i-1}, & j=1 \\
V N A_{j-1, a} \cdot\left(1+t_{j-1}\right)^{s m}-\sum_{i=p-s m}^{p-1}\left(\operatorname{Ing}_{i, j-1}-\operatorname{Cexpf}_{i, j-1}-\operatorname{Vajdm}_{i, j-1}\right) \cdot\left(1+t_{j-1}\right)^{p-i-1}, & j>1\end{array}\right.$ & \\
\hline$I n g_{i}=P m_{-} e_{i} N h_{-} e_{i}$ & (24) \\
\hline $\operatorname{Cexp}_{i}=C_{-} \operatorname{Eexp}_{-} e_{i} N h_{-} e_{i}$ & (25) \\
\hline$=\left\{\begin{array}{cc}N h_{i, j} \cdot 0,5 \cdot\left(L S 1_{i, j}-L S 2_{i, j}\right)+N h_{i, j} \cdot\left(L S 2_{i, j}-P m_{i}\right), & P m_{i}>L S 2_{i, j} \\
N h_{i, j} \cdot 0,5 \cdot\left(L S 1_{i, j}-P m_{i}\right), & L S 1_{i, j} \leqslant P m_{i} \leqslant L S 2_{i, j} \\
0, & L I 1_{i, j} \leqslant P m_{i} \leqslant L S 1_{i, j} \\
N h_{i, j} \cdot 0,5 \cdot\left(L I 1_{i, j}-P m_{i}\right), & L I 2_{i, j} \leqslant P m_{i} \leqslant L I 1_{i, j} \\
N h_{i, j} \cdot 0,5 \cdot\left(L I 1_{i, j}-L I 2_{i, j}\right)+N h_{i, j} \cdot\left(L I_{i, j}-P m_{i}\right), & P m_{i}<L I 2_{i, j}\end{array}\right.$ & \\
\hline $\begin{array}{l}t_{j}=S B_{j}+\Delta t_{j} \\
K_{j}=\frac{t_{j}\left(1+t_{i}\right) R_{j}}{\left(1+t_{j}\right)^{V R_{j}}-1}\end{array}$ & $\begin{array}{l}(27) \\
(28)\end{array}$ \\
\hline
\end{tabular}

3. Adaptation of the RD 413/2014 economic model to the SCSPS specificities and methodology for determining its impact on the income statement

Being the Revenue $_{i}$ the output variable of the model in Fig. 3 and Table 4, additional calculations are needed to assess its impact on the income statement of the facilities. The resulting combined calculation scheme is shown in Fig. 5.

For ease of understanding, the model in Fig. 3 has been included in the global representation of Fig. 5 using a simplified conceptual approach. It has been represented by means of two main blocks, namely, "Physical model" and "Economic model". The outputs of the first bloc are variables of physical nature that enter the second bloc, which in turn renders the Revenue $_{i}$ of the facility. For completeness, the global calculation scheme of Fig. 5 was prepared to deal also with the former regulatory frameworks in force prior to the RD $413 / 2014$, so the input parameters were accordingly directed to different inlet boxes "1998-2013 Regulatory parameters" and "2014 Regulatory parameters".

The portion of Fig. 5 in charge of assessing the impact of the Revenue $_{i}$ on the income statement of the assets is also conceptually subdivided into several blocks, i.e., the "Operating cost model", the "Depreciation and financial model", the "Taxation model" and the "Income statement model". The "Operating cost model" receives as input parameters the operation and maintenance variable cost $\left(V_{-} O M C_{a+1}\right)$, the fixed cost within the year $a+1\left(F_{-} O M C_{a+1}\right)$ and the electricity taxes, i.e., the taxes on the produced energy $\left(\operatorname{Tax}_{-} E\right)$ and on the retribution of the produced energy $\left(\operatorname{Tax}_{-} R\right)$. In addition, it produces the total operating cost (Operating_Cost $t_{i}$ ) as output variable. The inputs to the "Depreciation and financial model" are the investment cost (Inv_Cost), the eq- uity (Equity), the loan fixed interest rate (Int_Rate), the number of years to replace the debt or term of the loan (nyrd) and the number of years for the depreciation (nd). In turn, this sub-block computes as output

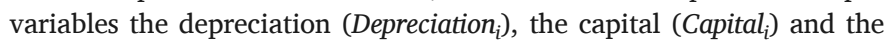
interests (Interest $s_{i}$ ) in the year $i$. The inputs to the "Taxation model" are the rate of corporate tax (Tax_Rate) and the earnings before interests and taxes $\left(E B I T_{i}\right)$, and the output is the corporate tax (Corp_Tax). The discount rate (Discount_Rate) along all the outputs of the previous blocks enter the "Income statement model", which renders the treasury position (Treasury $y_{i}$ ) and other widely used indicators for investment appraisal, i.e., the project net present value (NPV) (Project_NPV) and the project IRR (Project_IRR). Additionally, the cost to the SES of the remuneration of the facility over its $V U$ is also calculated (Total_Cost_SES). For the sake of brevity, the formulation of the above described variables has been here omitted for being well-known standard procedures easily available in basic financial textbooks.

The feasible application of the combined model in Fig. 5 is based on the assumption that all its inputs are known and can be supplied either by the regulations of the SES or by the owner of the facility. In this case, however, the inner characteristics and the present juncture of the SCSPS made impossible to obtain all the data needed to apply the model in Fig. 5. When compared with the 61,345 GCPVS totalling 4673 MW of installed capacity which came to exist in Spain, the 50 CSPP with $2300 \mathrm{MW}$ of installed capacity are certainly a small number that could make it easy to ascertain the identity of the study participants. Reasonably, the still ongoing juridical battle in terms of ISDS against Spain has made the SCSPS reluctant to supply sensible data such as the Inv_Cost, the Nh inst $_{i}$, the actual value of the total operating cost per unit of generated energy in the year $i\left(C_{-} E_{\text {exp_ }}\right.$ Real $\left._{i}\right)$, the Equity, the Int_Rate and other financial parameters. 


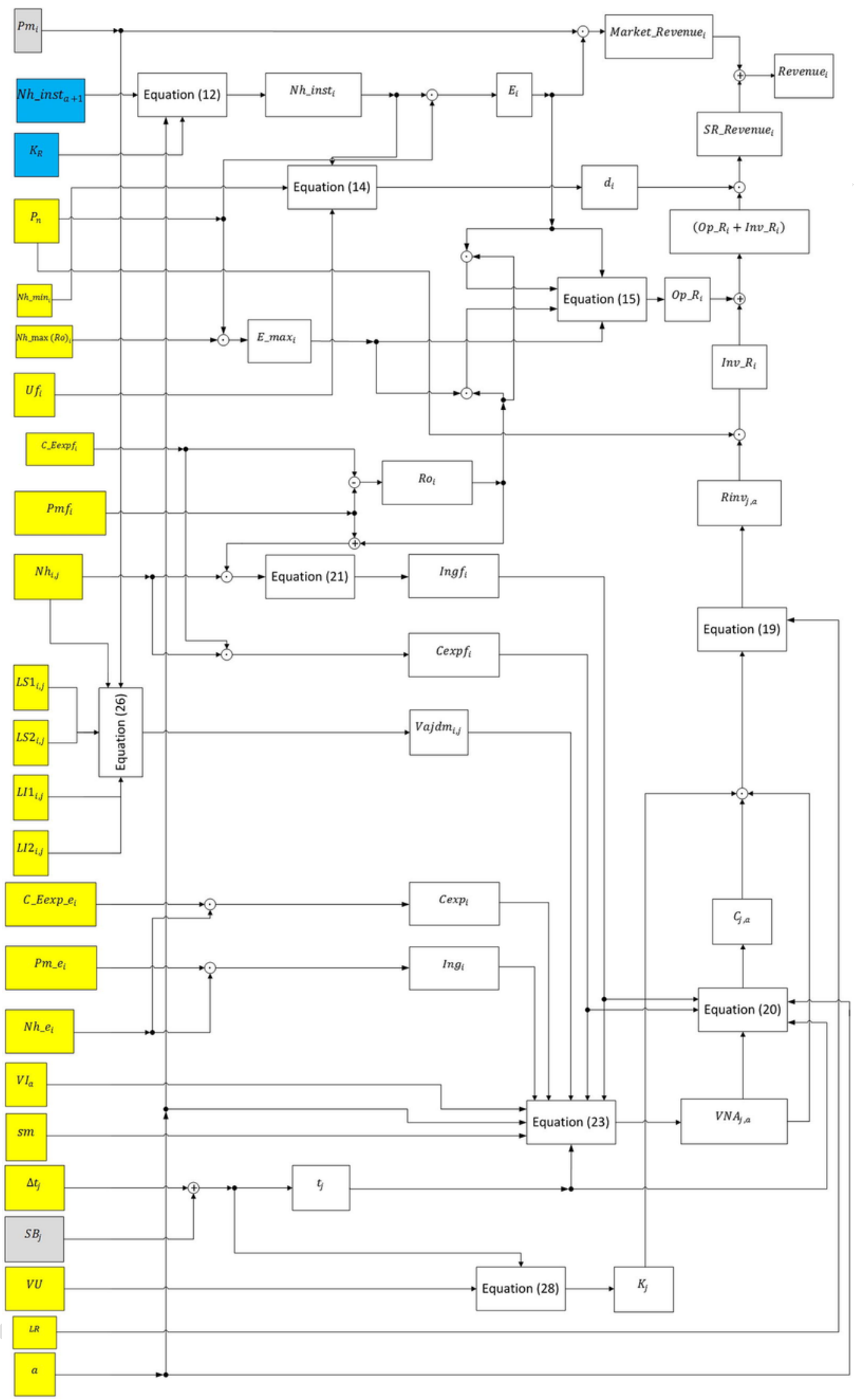

Fig. 3. Conceptual approach to the new RD 413/2014 economic and regulatory framework. Source: self-elaboration based on [110]. 


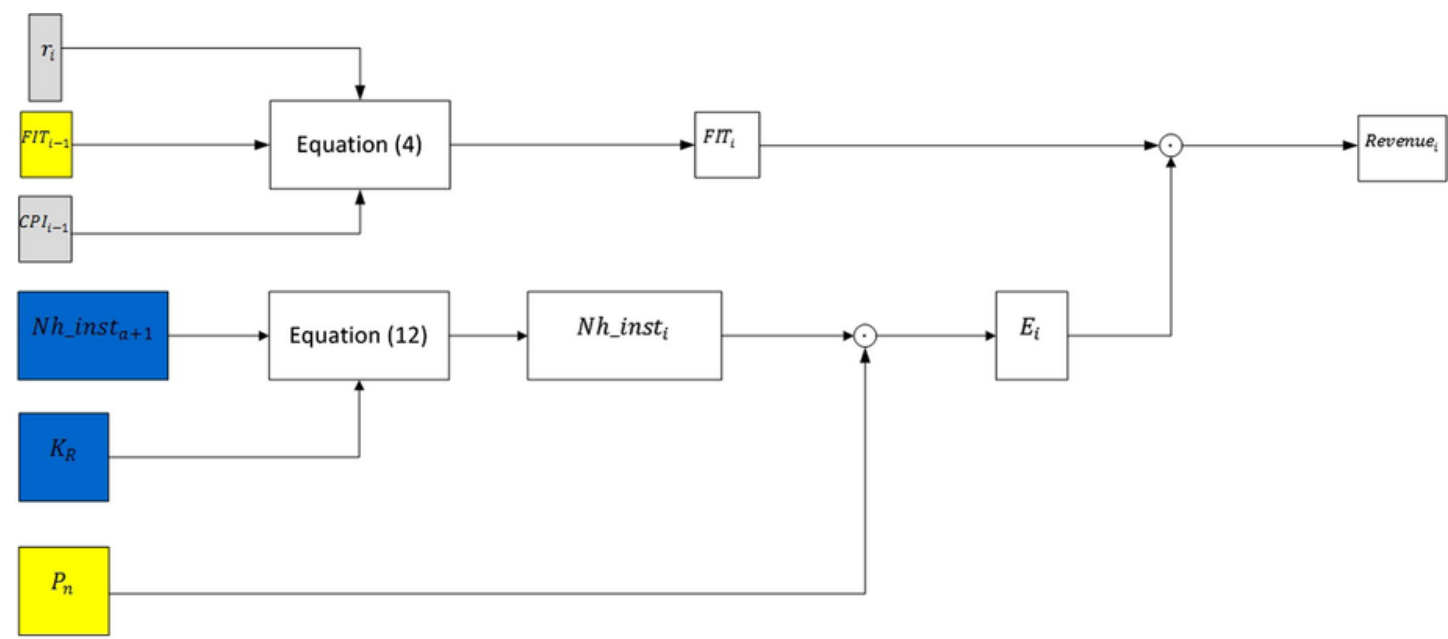

Fig. 4. Conceptual approach to the former RD 661/2007 economic and regulatory framework. Source: self-elaboration based on [107].

Regulatory parameters or standard parameters Financial/Economic parameters or data

Physical Parameters that might be uncertain

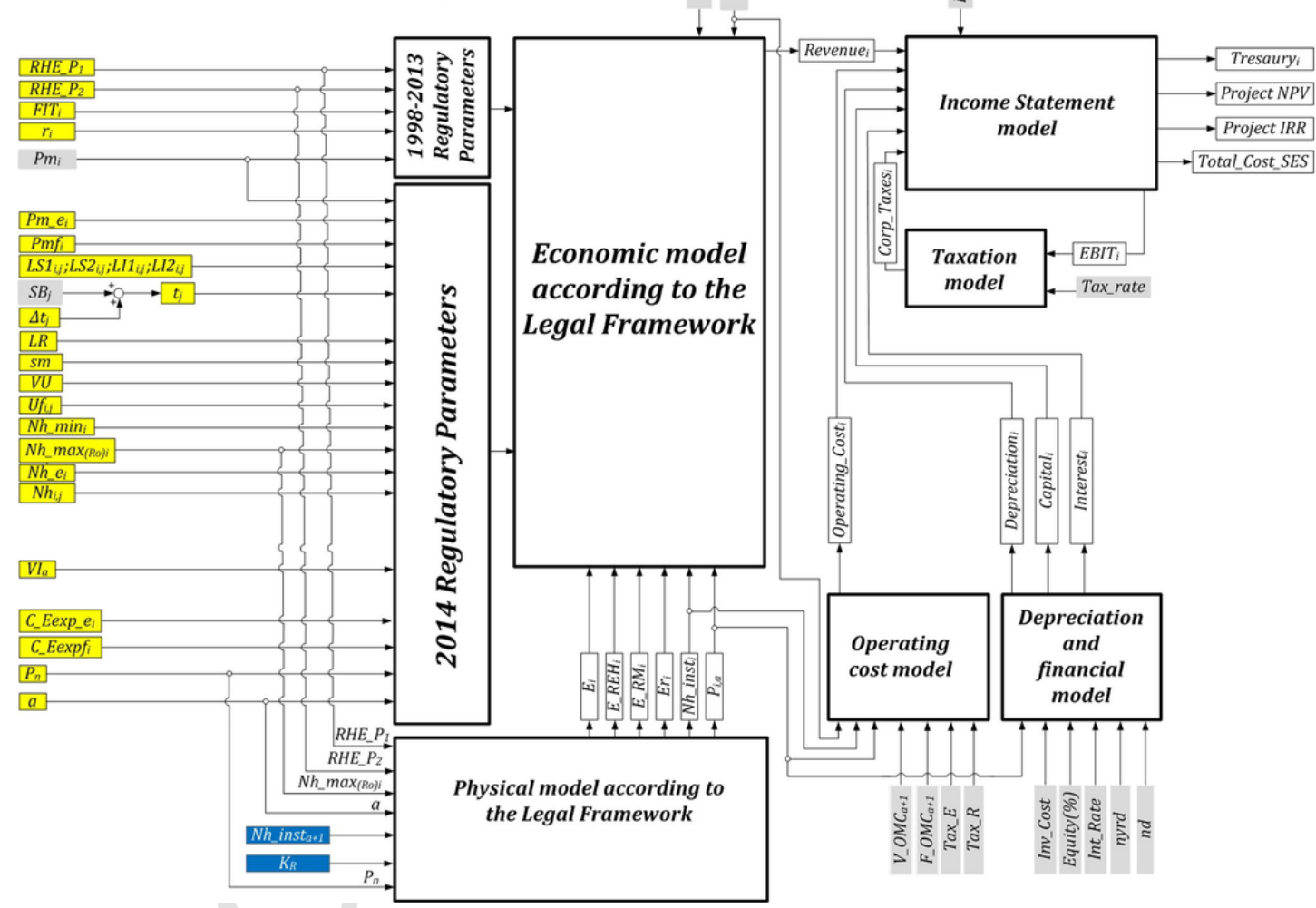

Fig. 5. Conceptual scheme for calculating the impact of the economic and regulatory frameworks on the income statement of the facilities. Source: Self-elaboration.

In order to overcome the lack of data it was necessary to adapt the model in Fig. 5 to deal with deviations or increments from the standard values assigned in the regulations to Inv_Cost, Nh_inst $t_{i}$ and $C_{-} E_{-} \exp _{-}$Real $_{i}$, and to set plausible scenarios for the financial parameters. Thus, the following approach was taken for Inv_Cost:

$$
I n v_{-} \text {Cost }=V I_{a}+\Delta V I_{a}
$$

$\Delta V I_{a}=V I_{a} \cdot \Delta V I_{a}(\%)$ where $\Delta V I_{a}$ is the deviation or increment of Inv Cost from its standard value $V I_{a}$ recognized in the MO IET 1045/2014 and $\Delta V I_{a}(\%)$ is the percentage value of $\Delta V I_{a}$.

Likewise, proceeding in the same way for Nh_inst:

$N h \_i n s t_{i}=N h \_s t d_{i}+\Delta N h \_s t d_{i}$ 


$$
\begin{aligned}
& N h \_s t d_{i} \\
& \quad\left\{\begin{array}{cc}
N h \_e_{i}, & a+1 \leqslant i \leqslant 2012 \\
N h \_e_{2013}+N h_{2013,1}, & i=2013 \\
N h_{i, j}, & 2014 \leqslant i \leqslant a+V U
\end{array}\right.
\end{aligned}
$$

$\Delta N h \_s t d_{i}=N h \_s t d_{i} \cdot \Delta N h \_s t d_{i}(\%)$

where $N h_{-} s t d_{i}$ is the standard value of $N h_{-}$inst $t_{i}$ set by the MO IET 1045/ 2014, $\Delta \mathrm{Nh}_{-} s t d_{i}$ is the deviation of $N h_{-}$inst $_{i}$ from $N h_{-} s t d_{i}$ and $\Delta N h_{-} s t d_{i}(\%)$ is the percentage value of $\Delta N h_{-} s t d_{i}$.

And finally, C_Eexp_Real:

$C \_E e x p \_R e a l_{i}=C \_E e x p \_s t d_{i}+\Delta C \_E e x p \_s t d_{i}$

$$
\begin{aligned}
& \text { C_Eexp_std } \\
& =\left\{\begin{array}{c}
C \_E \text { Exp_e } e_{i} \\
C \_E e x p \_e_{2013} \cdot\left(\frac{N h \_e_{2013}}{N h \_e_{2013}+N h_{2013,1}}\right)+C \_E e x p f_{2013} \cdot\left(\overline{N h \_}\right. \\
C \_E \operatorname{Expf} f_{2014} \cdot\left(1+\Delta \_s t d \_C o s t\right)^{(i-2014)}
\end{array}\right.
\end{aligned}
$$

$$
\Delta C \_E e x p \_s t d_{i}=C \_E e x p \_s t d_{i} \cdot \Delta C_{E^{2} e_{p} p_{s t d}}(\%)
$$

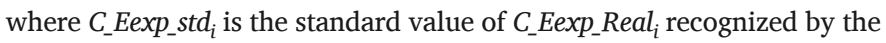
MO IET 1045/2014, $\Delta_{-} s t d \_$Cost is the per unit yearly increment on $C_{-} E$ $\operatorname{expf}_{i}$ from 2014 on, ${ }^{11}{ }_{\Delta} \mathrm{C}_{-}$Eexp_std $_{i}$ is the deviation of $C_{-}$Eexp_Real $_{i}$ from $C_{-} \operatorname{Eexp}_{-} s t d_{i}$ and $\Delta C_{-} \operatorname{Eexp}_{-} s t d_{i}(\%)$ is the percentage value of $\Delta C_{-} \operatorname{Eexp}_{-} s t d_{i}$. As regards the possible deviation $\Delta P m f_{i}$ between $P m_{i}$ and $P m f_{i}$ :

$$
P m_{i}=P m f_{i}+\Delta P m f_{i}
$$

It has been assumed to be null, either expressed in absolute value on in percentage value $\left(\Delta P m f_{i}(\%)\right)$, in the belief that the regulatory mechanism in Eq. (26) will compensate the deviations.

\section{Analysis of the economic impact of the RD 413/2014 new regulatory framework applied to the SCSPS: Case study of a $50 \mathrm{MW}$} facility

\subsection{Applied methodology}

In order to have a better insight of the economic impact of the RD $413 / 2014$ on the SCSPS it was decided to choose the most representative facility type for this analysis. As Table 2 and Fig. 1 show, 44 out of the 50 CSPP in Spain correspond to the parabolic trough technology, accounting for more than $95 \%$ of the installed capacity. Even more, above $60 \%$ of the parabolic trough CSPP do not have a thermal storage system. Within this category, the type facility code $I T-00,604$ is the most numerous group, totalling 14 CSPP (see Fig. 1).

Once the most representative type facility IT-00,604 was selected, the values of its regulatory parameters were extracted from the MO IET $1045 / 2014$ and listed in Table 5. Then, to study the impact of the new RD 413/2014 framework on the income statement of a type facility IT-

\footnotetext{
11 The IET 1045/2014 contemplated a fixed annual increment of $1 \%$ for $C_{-} \operatorname{Eexpf}_{i}$ from 2014 on, but excluding the items related to the taxes on the generated energy and on the remuneration of the generated energy. The simplified approach of (35) increments

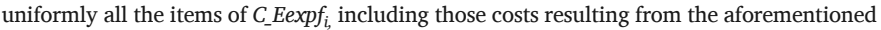
taxes.
}

00,604, all the necessary data was identified and classified into two different groups. The first group comprised those parameters that were assumed to be known and constant throughout all the analysis, which included both financial parameters and also regulatory parameters of the previous RD 661/2007 framework (see Table 6). The set of selected values for the financial parameters correspond to a realistic scenario in line with the economic reality of the SCSPS.

On the other hand, the second group of data corresponds to those variables and parameters identified in Section 3 as unknown, either due to the reluctance of the SCSPS to provide data (Inv_Cost, Nh_inst ${ }_{i}, C_{-} E e x-$ $p_{-}$Real ${ }_{i}$, Equity and Int_Rate) or due to regulatory uncertainty $\left(L_{R}\right)$.

Due to the complexity of the study to undertake, it was addressed in different consecutive stages. The applied methodology has been summarized in Fig. 6.

As it can be seen in Fig. 6, the first stage of the study was aimed to determine the financial boundaries of the considered IT-00,604 type facility. Once evaluated, the second stage was focused on determining the economic impact of the financial regulatory parameters, in order to analyse whether they could affect the economic viability of the energy asset. Next, the third stage was intended to determine the economic impact of the deviation of the main economic regulatory parameters from their standard values assigned in the regulatory scheme. And finally, the fourth stage studied the economic impact of the deviation of the energy production from its standard value.

\subsection{Assessment of the results of the first stage of analysis: The financial} boundaries

In the first stage of analysis, the financial boundaries of the IT-00,604 type facility were determined. No deviation from the standard values of the MO IET 1045/2014 parameters was assumed, and a set of different scenarios of the financial structure was considered to determine the treasury and the IRR evolution (see Table 7). Particularly, the value of $\Delta t_{j}$ was set to zero, which is the worst case for the facilities, and consequently $t_{j}$ matches $S B_{j}$ (see Eq. (27)). Concerning $S B_{j}$, it was considered constant during the $V U$ of the CSPP and equal to its average during the 10-year period 2006-2015 (see Fig. 7).

Fig. 8 shows the evolution of the treasury for different combinations of the Equity and the Int_Rate and for two distant $L_{R}$ values $\left(L_{R}=2 \%\right.$ in the upper subplot and $L_{R}=8 \%$ in the lower subplot). It is remarkable the great impact on the treasury evolution of the financial structure of the analysed energy asset, even when no deviation from the standard value of the parameters is considered. That is, the viability of even though those facilities literally qualified by the RD 413/2014 as "efficient and well managed" exhibit great sensitivity to the financial parameters.

All the analysed cases pointed to the same pair (Equity $=25 \%$, IntrRate $=5 \%$ ) as the threshold to avoid bankruptcy. Lower values of $E q$ uity or higher values of Int_Rate can make the facility to become bankrupt. The influence of $L_{R}$ is only manifested in the particular time evolution of the treasury and the depth of the financial shortage (see Fig. 8). As a result, the pair (Equity $=25 \%$, Int_Rate $=5 \%$ ) will be established as the financial boundary for the analysed type facility from here on through the remaining stages of the study.

Regarding the evolution of the IRR, the results indicate that even an "efficient and well managed plant" would see its profitability decreased when compared with the obtained under the former regulatory framework. For the same cases listed in Table 7, Fig. 9 shows the evolution of the IRR in front of the financial parameters, first under the previous RD 661/2007 framework (upper subplot), and then under the new RD 413/2014 (lower subplot). The obtained IRR values form surfaces, which have been subdivided into coloured regions according to the legend at the base of each of the subplots. 
Table 5

Values of the regulatory parameters for a type facility IT-00604.

Source: self-elaboration based on: [111].

\begin{tabular}{|c|c|c|c|c|c|c|c|c|c|c|c|c|}
\hline$a$ & $\begin{array}{l}V U \\
\text { [years] }\end{array}$ & $K_{R}(\%)$ & $\begin{array}{l}V I_{a} \\
{[€ / \mathrm{MW}]}\end{array}$ & $C_{1 . a}$ & $\begin{array}{l}\operatorname{Rinv}_{2013} \\
\text { [€/MWh] }\end{array}$ & $\operatorname{Rinv}_{2014-2016}[\mathrm{E} / \mathrm{MWh}]$ & $N h \max _{(\mathrm{RoO} 2013}[\mathrm{h}]$ & $\begin{array}{l}N_{h} \max _{(R o)} \\
2014-16[\mathrm{~h}]\end{array}$ & $\begin{array}{l}\text { Nh_min }{ }_{2013} \\
{[\mathrm{~h}]}\end{array}$ & $\begin{array}{l}\text { Nh_min } \min _{2014-16} \\
{[\mathrm{~h}]}\end{array}$ & $U f_{2013}[\mathrm{~h}]$ & $\begin{array}{l}U f_{2014-16} \\
{[\mathrm{~h}]}\end{array}$ \\
\hline 2012 & 25 & 0.2 & $4,576,096$ & 1 & 192,265 & 410,391 & 956 & 2040 & 245 & 1224 & 143 & 714 \\
\hline Year & $\begin{array}{l}P m_{-} e_{i} \\
{[€ / \mathrm{MWh}]}\end{array}$ & $\begin{array}{l}\text { C_Eexp_e } e_{i} \\
\text { [€/MWh] }\end{array}$ & $\begin{array}{l}P f m_{i} \\
{[€ / \mathrm{MWh}]}\end{array}$ & $\begin{array}{l}C_{-} \operatorname{Eexpf}_{i} \\
{[€ / \mathrm{MWh}]}\end{array}$ & $N h e_{i}[\mathrm{~h}]$ & $N h_{i j}[\mathrm{~h}]$ & $L S 2_{i j}[€ / \mathrm{MWh}]$ & $\begin{array}{l}L S 1_{i, j} \\
{[€ / \mathrm{MWh}]}\end{array}$ & $\begin{array}{l}L I 1_{i, j} \\
{[€ / \mathrm{MWh}]}\end{array}$ & $\begin{array}{l}L I 2_{i, j} \\
{[€ / \mathrm{MWh}]}\end{array}$ & $\begin{array}{l}R o_{i} \\
{[€ / \mathrm{MWh}]}\end{array}$ & \\
\hline 2012 & & & & & & & & & & & & \\
\hline 2013 & 296.44 & 105.10 & - & 91.85 & 17 & 956 & & & & & 39.495 & \\
\hline 2014 & & & 49.21 & 88.90 & & 2040 & 57.37 & 53.29 & 45.13 & 41.04 & 39.694 & \\
\hline 2015 & & & 50.55 & 89.64 & & 2036 & 58.71 & 54.63 & 46.46 & 42.38 & 39.090 & \\
\hline 2016 & & & 50.78 & 90.52 & & 2032 & 58.99 & 54.86 & 46.70 & 42.61 & 39.745 & \\
\hline 2017 & & & 53.08 & 91.39 & & 2028 & 61.24 & 57.16 & 48.99 & 44.91 & & \\
\hline
\end{tabular}


Table 6

Financial and previous RD 661/2007 framework constant parameters for the study. Source: Self-elaboration based on [107].

Constant parameters

\begin{tabular}{|c|c|}
\hline \multicolumn{2}{|l|}{ Financial parameters } \\
\hline Loan repayment system & $\begin{array}{l}\text { Linear } \\
\text { method }\end{array}$ \\
\hline Loan grace period (years) & 1 \\
\hline nyrd (years) & 15 \\
\hline Discount_Rate (\%) & 5 \\
\hline nd (years) & 10 \\
\hline$C P I_{i}(\%)$ & 2.5 \\
\hline Tax_rate $(\%)$ & 25 \\
\hline \multicolumn{2}{|l|}{ RD 661/2007 and subsequent amendments parameters } \\
\hline $\mathrm{FIT}_{a}[\mathrm{c} € / \mathrm{kWh}]$ & 26.9375 \\
\hline FIT $_{a+25}[\mathrm{c} € / \mathrm{kWh}]$ & 21.5498 \\
\hline Useful life (years) & 40 \\
\hline$r_{i}$ & $\begin{array}{l}25 \text { basis } \\
\text { points until } \\
2012 \\
50 \text { basis } \\
\text { points from } \\
2013\end{array}$ \\
\hline $\begin{array}{l}\Delta_{-} C P I_{i}(\%)=C P I_{i}-C P I_{i}^{\prime}\left(C P I_{i}^{\prime}: C P I_{i} \text { at constant tax excluding }\right. \\
\text { unprocessed food and energy products) }\end{array}$ & $0.5 \%$ \\
\hline $\operatorname{Tax}_{-} E[€ / \mathrm{MWh}]$ & 0.5 \\
\hline $\operatorname{Tax}_{-} R(\%)$ & 7 \\
\hline
\end{tabular}

When both subplots are compared, it is obtained an IRR reduction under the new RD 413/2014 framework of no less than 4\% in the best cases. Furthermore, only values of $L_{R}$ higher than $6 \%$ could guarantee and IRR above 4\%, regardless the Equity and Int_Rate of the "efficient and well managed" considered plant.

4.3. Assessment of the results of the second stage of analysis: The impact of the financial regulatory parameters

Next, once the financial boundaries were determined, the attention was focused on assessing the impact of the financial regulatory parameters. Despite the assumption that some of the actors of the SCSPS may have had in the past that the values of $L_{R}$ and $t_{j}$ would be around $7 \%$ during the $V U$ of the assets, their evolution might be quite uncertain in the short term [114]. In this regard, this stage is aimed to analyse to what extent these parameters might affect the economic viability of an "efficient and well managed" plant. Therefore, here it will be assumed that no deviation from the standard values of the MO IET 1045/2014 parameters is produced, the financial non-regulatory parameters Equity and Int_Rate are set to its theoretical limits of $25 \%$ and 5\%, respectively, and $L_{R}$ and $t_{j}=S B_{j}$ change as described in Table 8 .

As can be seen in the middle subplot of Fig. $10, L_{R}=4 \%$ is the threshold at which bankruptcy is avoided for all the $t_{j}=S B_{j}$ values. For lower values of $L_{R}$, the asset can go bankrupt for certain $t_{j}=S B_{j}$ cases (see Fig. 10, upper subplot). Therefore it is plain the key role of the regulatory $L_{R}$ parameter in the financial viability of the facilities, even to a greater extent than $S B_{j}$.

Concerning the evolution of the IRR and NPV (see upper and lower subplots of Fig. 11, respectively), the results show again the greater impact of the regulatory parameter $L_{R}$. The IRR and NPV surfaces exhibit a greater slope along the $L_{R}$ axis, showing the stronger influence of this parameter. Specifically, the $L_{R}=4 \%$ financial threshold correspond to IRR values up to $2 \%$, but to negative NPV values. Due to the $5 \%$ discount rate used in the analysis, only $L_{R}$ values above $7 \%$ render positive values for the NPV (see Fig. 11, lower subplot). Consequently, the importance of the values regulatory assigned to $L_{R}$ is evidenced.

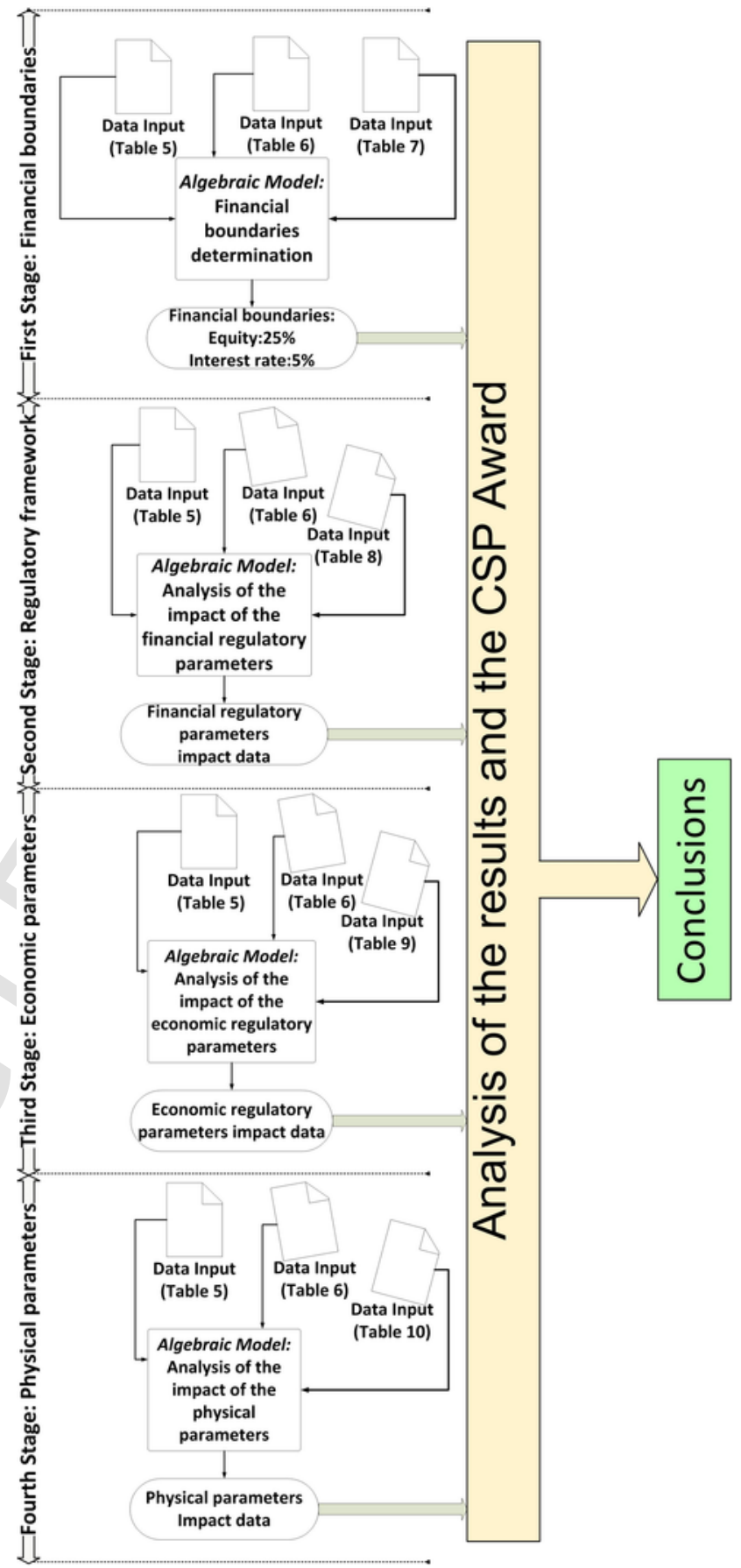

Fig. 6. Methodology for the analysis of the economic impact of the RD 413/2014 new regulatory framework on the CSPP. Source: Self-elaboration.

\subsection{Assessment of the results of the third stage of analysis: The impact of the economic regulatory parameters}

As previously said, "efficient and well managed plants" are those whose investment and operating costs comply with the standard values set in the MO IET/1045/2014. Also, the analyses carried out so far have shown how the economic results of the "efficient and well managed plants" can be seriously affected depending on the values of the financial regulatory parameters. According to this, the economic results of an actual plant, whose investment and/or operating costs may have deviations from the standard costs values set in the MO IET/1045/ 
Table 7

Range of values of the parameters for the financial boundaries determination.

Source: Self-elaboration.

\begin{tabular}{|c|c|c|}
\hline \multicolumn{3}{|c|}{ Financial boundaries analysis } \\
\hline Parameter & Range & Incremental step \\
\hline$\Delta V I_{a}(\%)$ & $0 \%$ & - \\
\hline$\Delta N h \_s t d_{i}(\%)$ & $0 \%$ & - \\
\hline$\Delta C_{-} \operatorname{Eexp}_{-} s t d_{i}(\%)$ & $0 \%$ & - \\
\hline$\Delta P m f_{i}(\%)$ & $0 \%$ & - \\
\hline$\Delta t_{j}(\%)$ & $0 \%$ & - \\
\hline$t_{j}=S B_{j}(\%)$ & $4 \%$ & - \\
\hline Equity(\%) & {$[0,100] \%$} & $25 \%$ \\
\hline Int_Rate (\%) & {$[5,10] \%$} & $2.5 \%$ \\
\hline$L_{R}(\%)$ & {$[1,8] \%$} & $1 \%$ \\
\hline
\end{tabular}

2014, could experience even a greater impact. In this regard, this third stage of analysis was aimed to determine the impact of the main economic regulatory parameters on the economic results of those plants whose investment and operation and maintenance costs differ from the standard values set in the MO IET/1045/2014, for the scenarios listed in Table 9.

Fig. 12 demonstrate the effect of the deviations $\Delta V I_{a}$ and $\Delta C_{-}$Eexp_std $_{i}$ on the liquidity of the analysed CSPP. The results indicate that even in the case of the best financial regulatory situation $\left(L_{R}=8 \%\right), \Delta V I_{a}=30 \%$ can lead to a bankruptcy situation. With $\Delta V I_{a}=30 \%$, bankruptcy can only be avoided in the unlikely event of $\Delta C_{-} \operatorname{Eexp}_{-} s t d_{i}=-50 \%$. Also, in the case $\Delta V I_{a}=0 \%$, deviations $\Delta C_{-} E_{\text {exp_std }}$ equal or higher than $25 \%$ lead likewise to a bankruptcy situation. In addition, the inspection of the results indicate that the impact of $\Delta V I_{a}$ on the treasury evolution is greater than that of $\Delta C_{-} E E_{0 x p} s t d_{i}$, being the worst case scenarios those with $\Delta V I_{a}$ above $30 \%$ and $\Delta C_{-}$Eexp_std $_{i}>0 \%$.

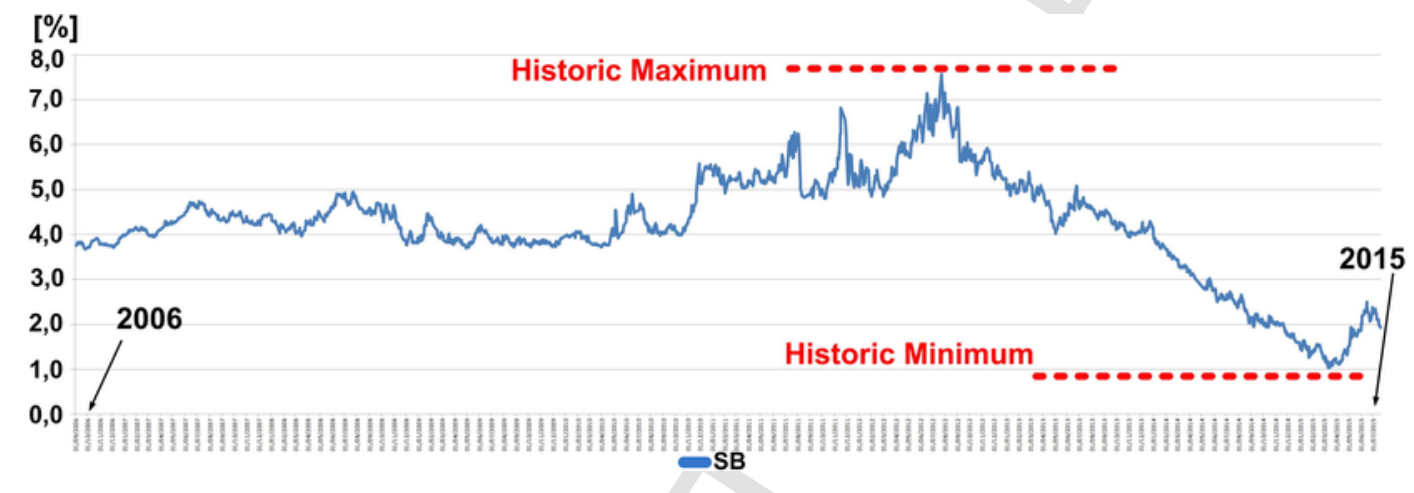

Fig. 7. Evolution of $S B_{j}$ during the 10-year period 2006-2015.
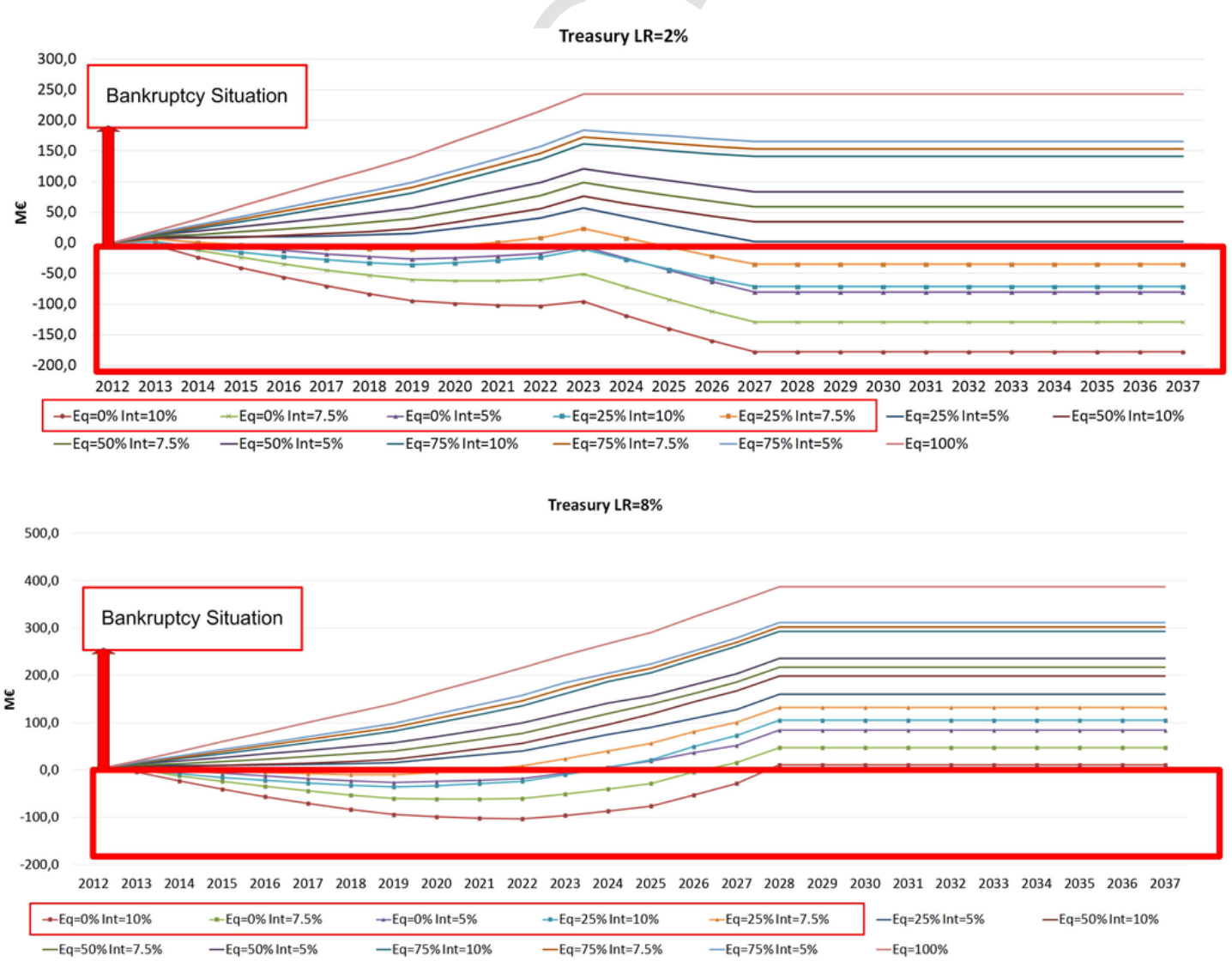

Fig. 8. Treasury evolution for different Equity and Int_Rate values and for two distant $L_{R}$ values (upper subplot: $L_{R}=2 \%$, lower subplot: $L_{R}=8 \%$ ). Source: self-elaboration. 
a) IRR Evolution: RD 661/2007

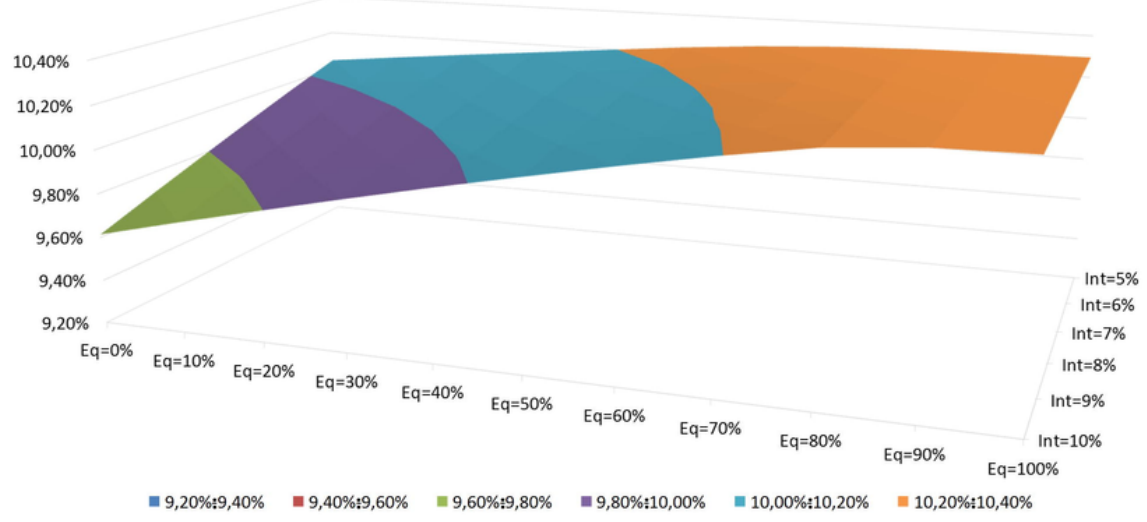

b) IRR Evolution: Financial Scenario

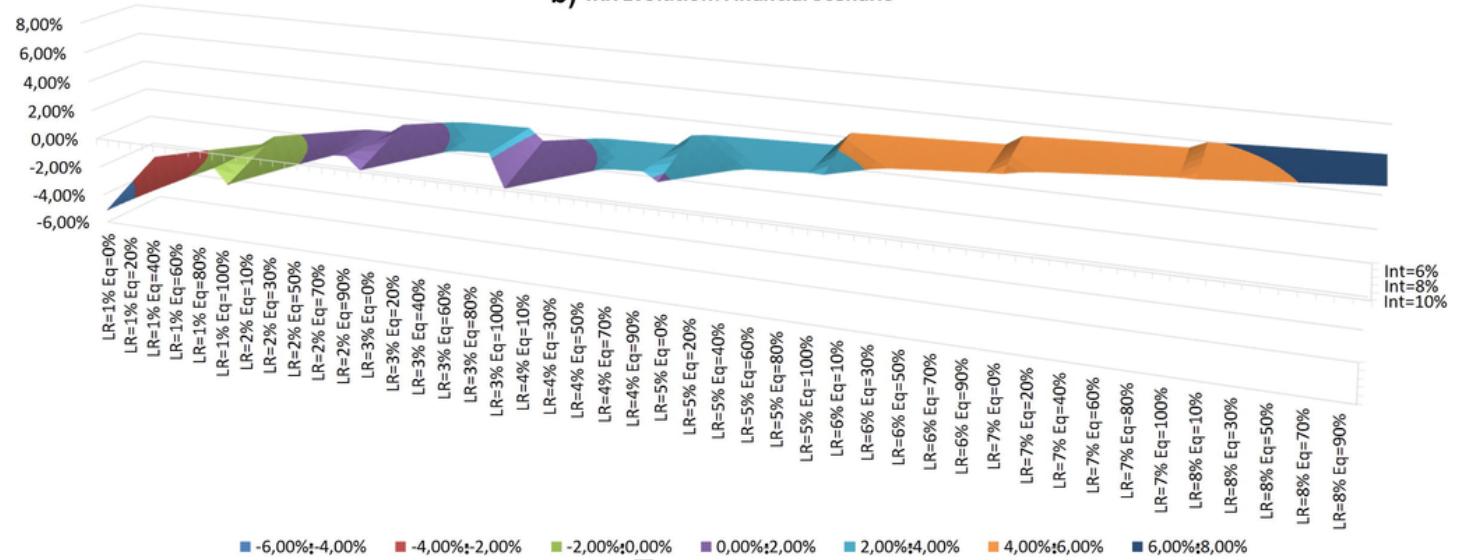

Fig. 9. IRR evolution for different values of the economic parameters under the previous RD 661/2007 (upper subplot) and under the new RD 413/2014 (lower subplot). Source: self-elaboration.

Table 8

Range of values of the parameters for the determination of the impact of the financial regulatory parameters.

Source: Self-elaboration.

\begin{tabular}{lll}
\hline \multicolumn{2}{l}{ Impact of the financial regulatory parameters analysis } & \\
\hline Parameter & Range & Incremental step \\
\hline$\Delta$ II $_{a}(\%)$ & $0 \%$ & - \\
$\Delta N h_{-} s t d_{i}(\%)$ & $0 \%$ & - \\
$\Delta C$ Eexp_std $_{i}(\%)$ & $0 \%$ & - \\
$\Delta P f_{i}(\%)$ & $0 \%$ & - \\
$\Delta t_{j}(\%)$ & $0 \%$ & - \\
$t_{j}=S B_{j}(\%)$ & {$[1,8] \%$} & $1 \%$ \\
Equity(\%) & $25 \%$ & - \\
Int_Rate $(\%)$ & $5 \%$ & - \\
$L_{R}(\%)$ & {$[1,8] \%$} & $1 \%$ \\
\hline
\end{tabular}

As regards the IRR evolution, only from $L_{R}$ above $6 \%$ a significant amount of positive IRR values is obtained for the considered $\Delta V I_{a}$ and $\Delta C_{-} E_{\text {exp }} s t d_{i}$ ranges. The negative IRR values obtained with $L_{R}$ within $6 \%-7 \%$ correspond to $\Delta V I_{a}$ above $6 \%$ and $\Delta C_{-}$Eexp_std $_{i}$ above $30 \%$. Also, for $L_{R}$ within $6 \%-7 \%$ and $\Delta C_{-}$Eexp_std $_{i} \leq 0 \%$ mostly positive IRR values are obtained regardless the $\Delta V I_{a}$ value (see Fig. 13).

Concerning the evolution of the NPV, predominantly positive values are obtained for $L_{R}$ ranging within $6 \%$ and $8 \%$. Nevertheless, positive $\Delta V I_{a}$ and $\Delta C_{-}$Eexp_std $_{i}$ deviations exceeding certain thresholds can result in negative values for the NPV (see Fig. 14). Consequently, these results proof the importance of the deviations between the actual and the regulatory standard values of the investment and the operating costs, which can seriously diminish the profitability of the assets.

4.5. Assessment of the results concerning the fourth stage of analysis: The impact of the physical parameters

The economic impact of the deviation of the energy production from the regulatory standard value is indirectly assessed through the deviation in the standard number of equivalent operating hours at rated power $\Delta N h_{-} s t d_{i}$ (see Eqs. (11) and (31)). The considered set of scenarios is specified in Table 10.

Fig. 15 shows that the effect of the negative deviations $\Delta N h_{-} s t d_{i}$ on the treasury evolution is less important than that of $\Delta V I_{a}$ and $\Delta C_{-} E$ exp_std (compare with Fig. 12). Bankruptcy is only produced for $\Delta N h_{-} s t d_{i} \leq-20 \%$ and for the lower $L_{R}$ values within $1 \%$ and $2 \%$.

In the same way, the results of Figs. 16 and 17 clearly indicate the negligible effect of $\Delta N h_{-} s t d_{i}$ on the IRR and the NPV project.

4.6. Confronting the $R D 413 / 2014$ new regulatory framework with the last arbitral Award resolution applied to the SCSPS

In May 2017, there was the resolution of a particular case [104] regarding a dispute submitted to the ICSID based on the ECT. The Claimants were private limited companies that invested in CSP in Spain under the former framework RD 661/2007 and the Respondent was the Kingdom of Spain. Since the plants concerning this Award belonged to the type IT-000,604 here considered, the information contained in the 
100,0

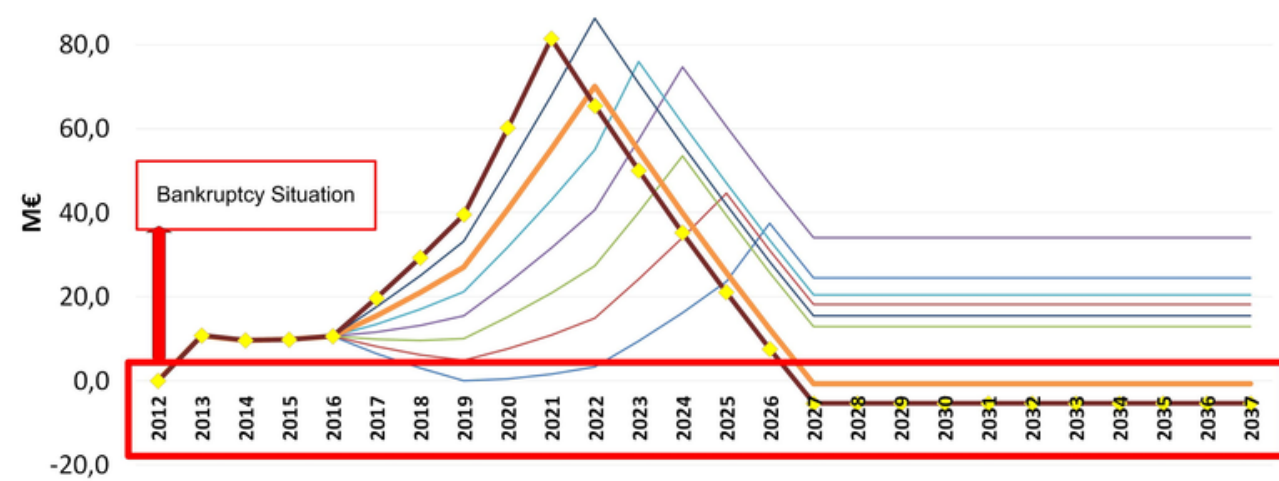

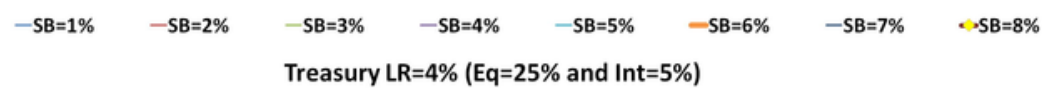

120

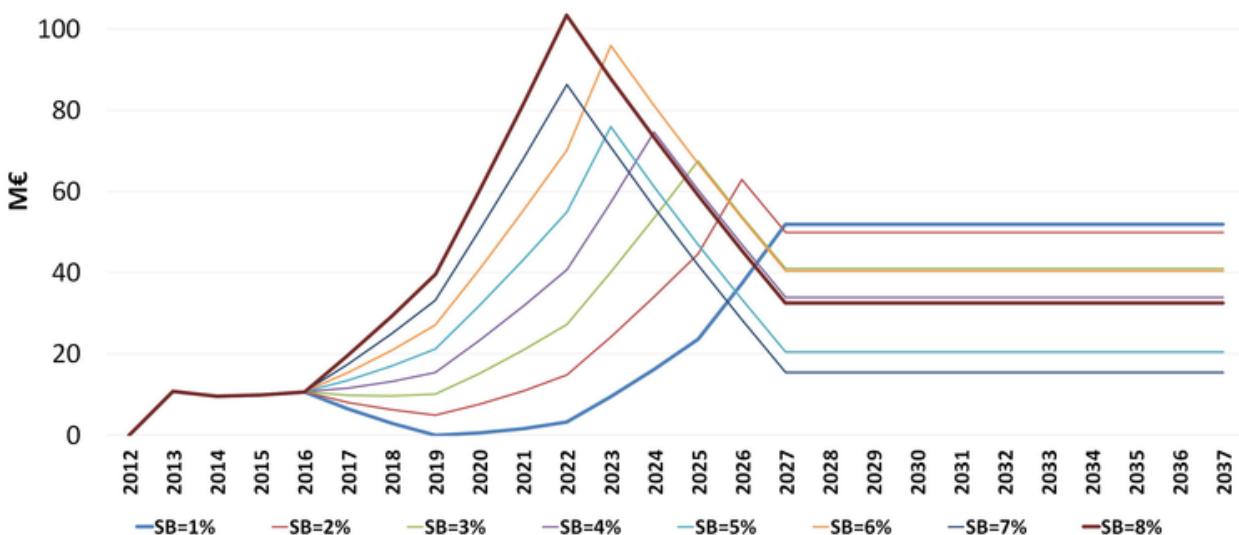

Treasury $\mathrm{LR}=8 \%(\mathrm{Eq}=\mathbf{2 5 \%}$ and $\mathrm{Int}=5 \%)$

300

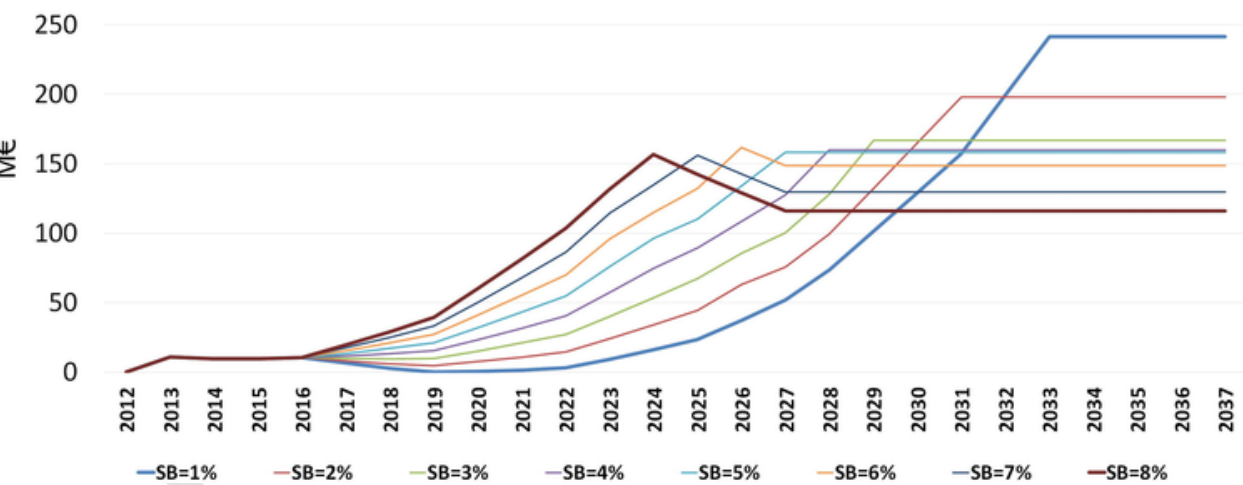

Fig. 10. Treasury evolution for different $t_{j}=S B_{j}$ values and for three $L_{R}$ values (upper subplot: $L_{R}=3 \%$, middle subplot: $L_{R}=4 \%$, lower subplot: $L_{R}=8 \%$ ). Source: self-elaboration.

Award proved useful to corroborate the results of the analysis presented in the previous subsections.

In essence, the Claimants requested a declaration that the Respondent had "violated Articles 10 and 13 of the ECT", as well as an "order that the Respondent make full reparation to the Claimants for the injury to its investments". This reparation could be in the form of "full restitution to the Claimants by re-establishing the situation which existed prior to Spain's breaches of the ECT" or "pay the Claimants com- pensation for all losses suffered as a result of Spain's breaches of the ECT".

In the Award the Tribunal concluded that only the claim invoking Article 10(1), i.e., "obligation to accord investors fair and equitable treatment" provided "the most appropriate legal context for assessing the complex factual situation presented". In this regard, one of the fundamental parts of the analysis of the Tribunal was to determine whether the Respondent had accorded Claimants fair and equitable 
Project IIR
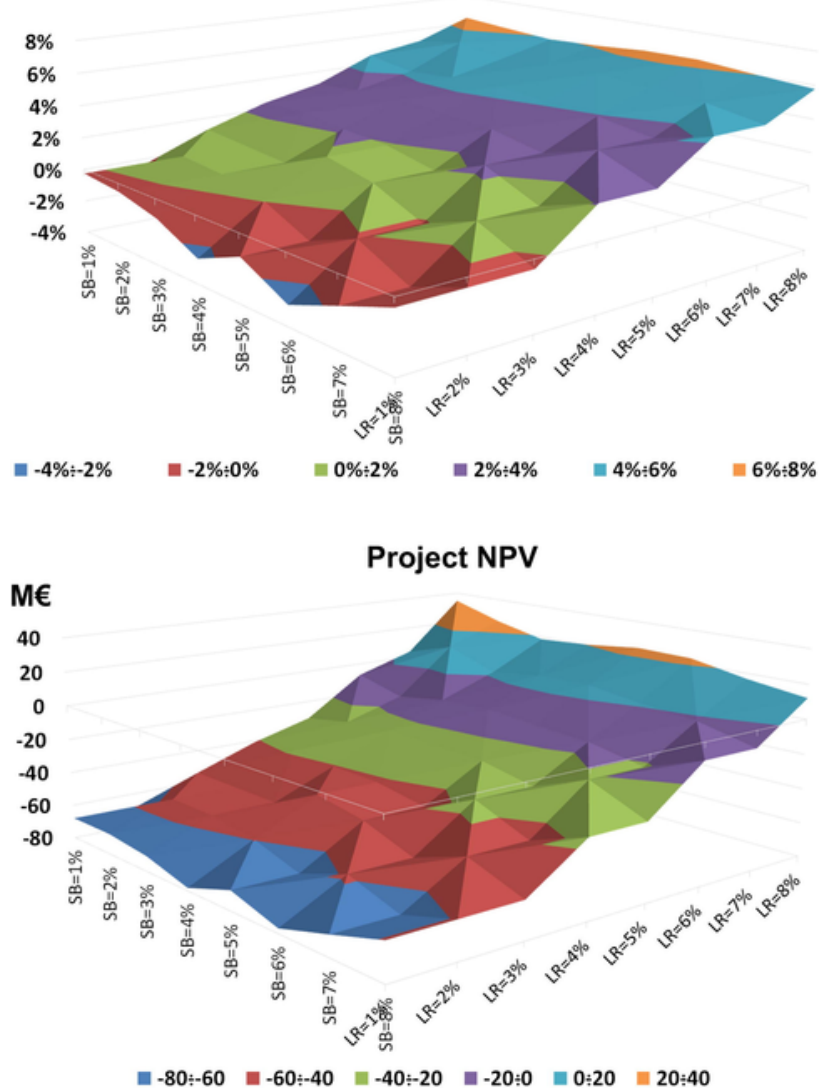

Fig. 11. Project IRR (upper subplot) and project NPV evolution (lower subplot) for different $L_{R}$ and $t_{j}=S B_{j}$ values. Source: Self-elaboration.

Table 9

Range of values of the parameters for the determination of the impact of the economic regulatory parameters.

Source: Self-elaboration.

\begin{tabular}{lll}
\hline \multicolumn{2}{l}{ Impact of the economic regulatory parameters analysis } & \\
\hline Parameter & Range & Incremental step \\
\hline$\Delta V I_{a}(\%)$ & {$[-30,30] \%$} & Treasury: $30 \%$ \\
& & NPV, IRR: $6 \%$ \\
$\Delta N h_{-} s t d_{i}(\%)$ & $0 \%$ & - \\
$\Delta C_{-} \exp _{-} s t d_{i}(\%)$ & {$[-50,50] \%$} & Treasury: $25 \%$ \\
$\Delta P f_{i}(\%)$ & $0 \%$ & NPV, IRR: $10 \%$ \\
$\Delta t_{j}(\%)$ & $0 \%$ & - \\
$t_{j}=S B_{j}(\%)$ & $4 \%$ & - \\
Equity $(\%)$ & $25 \%$ & - \\
Int_Rate (\%) & $5 \%$ & - \\
$L_{R}(\%)$ & {$[1,8] \%$} & - \\
\hline
\end{tabular}

treatment. In their analysis the Tribunal stated that "the state has a right to regulate, and investors must expect that the legislation will change" and therefore "the ECT did not bar Spain from making appropriate changes to the regulatory regime of $\mathrm{RD} 661 / 2007$ '. However the Tribunal clearly stated that "the ECT did protect Claimants against the total and unreasonable change that they experienced here".

In this point, the breach of treaty seems to rely on the adjectives "total" and "unreasonable". In first place, regarding the adjective "total", the Tribunal considered the new regulatory framework as "an unprecedented and wholly different regulatory approach, based on wholly different premises". The reasons behind this perception might be found by analysing the differences between Figs. 3 and 4 .

Concerning the adjective "unreasonable", the Tribunal stressed that had serious reservations regarding the fact that the new regulatory system was "based on a hypothetical "efficient" plant" with its "hypothetical costs of a hypothetical "efficient" plant". The other key point was the fact that the new regulatory scheme was addressed to alter the potential rate of return of the energy asset. On this subject the Tribunal said that "the Respondent's decision to alter the target rate of return potentially available to existing investors as done here casts into question the fairness and equity of the change to the new regime".

Actually, these two key aspects were strongly related and, as the Tribunal stated, "Respondent's idealized reasonable return was calculated on the basis of its officials' estimates of the asset values and costs of a hypothetical "standard installation"'. In other words "the new regime pays no regard to actual costs (including loan servicing) or actual efficiencies of specific existing CSP plants" and the Respondent "retroactively applied these "one size fits all" standards to existing facilities, like Claimants', that were previously designed, financed and constructed based on the very different regulatory regime of RD 661/2007."

Precisely, it is in this point where relies the other breach of treaty, because as the Tribunal stated, the case under discussion "contrasts with the position in AES v. Hungary in which the State developed a new regulatory approach for electrical generators that assessed the characteristics of individual plants, which was held not to be a breach of treaty".

That is the reason why the Tribunal declared that "this new system was profoundly unfair and inequitable as applied to Claimants' existing investment, stripping Claimants of virtually all of the value of their investment" and considered that "Article 10(1) of the ECT entitled them to expect that Spain would not drastically and abruptly revise the regime, on which their investment depended, in a way that destroyed its value".

In the resolution, the Tribunal stated that the Respondent violated Article 10(1) of the ECT "by failing to accord fair and equitable treatment to Claimants" and in consequence, the Tribunal awarded the Claimants a specified amount of money.

The analysis provided in Sections $4.2-4.5$ proves the impact of the new economic framework and the key role of the standard values assigned to its parameters. These results are also corroborated by the information included in the Award. According to the data provided, the Claimants invested in three CSP plants in Spain with equity ratios of $30 \%$ and $36.5 \%$, and with debt ratios of $70 \%$ and $63.5 \%$, respectively. In the same way, "the plants' historical capital costs were about $40 \%$ higher than the level deemed "efficient" under the new regime" and their operation and maintenance costs "were from $13 \%$ to $18 \%$ higher than those of the hypothetical "standard" plant." As a result of these deviations the plants had problems of liquidity and were forced into "debt rescheduling negotiations with their external lenders".

The situation of these plants is consistent with the results obtained in this analysis when applying similar deviations as described in the Award. Concerning the liquidity problems, the results in Fig. 12 show that for the abovementioned investment and operation and maintenance costs deviations the assets go into bankruptcy, even for high values of $L_{R}$.

In the same way, the low values of the project IRR project shown in Fig. 13 for this costs deviations are coincident with the low values of the pre-tax return described in the Award.

According to this, and extrapolating the analysis and the Award results to the entire SCSPS, it might be possible to assume that most of the CSPP subjected to financial debts should have had to renegotiate 


\section{Treasury $\mathrm{LR}=\mathbf{8} \% \Delta \mathrm{Pm}=\mathbf{0} \%$}

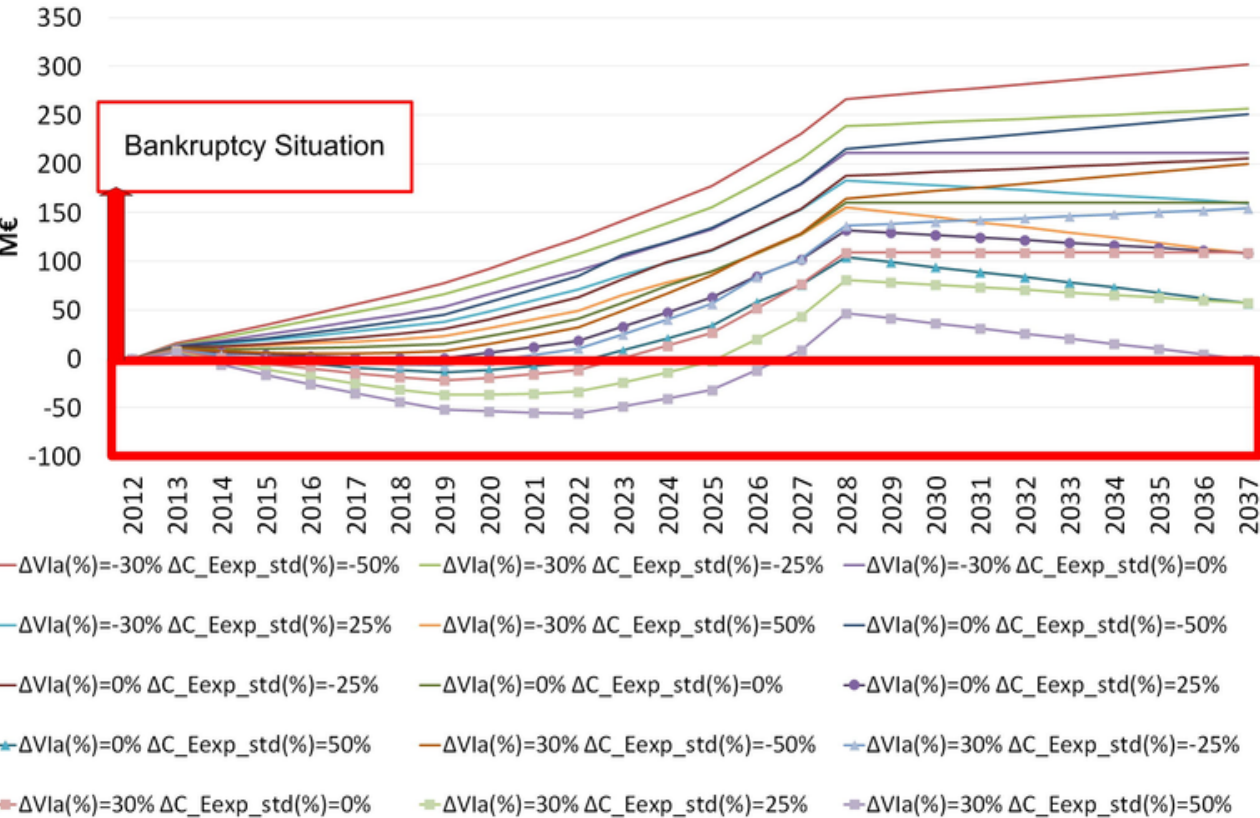

Fig. 12. Treasury evolution for different $\Delta V I_{a}$ and $\Delta C_{-} \operatorname{Eexp}_{-} s t d_{i}$ values and for $L_{R}=8 \%$. Source: self-elaboration.

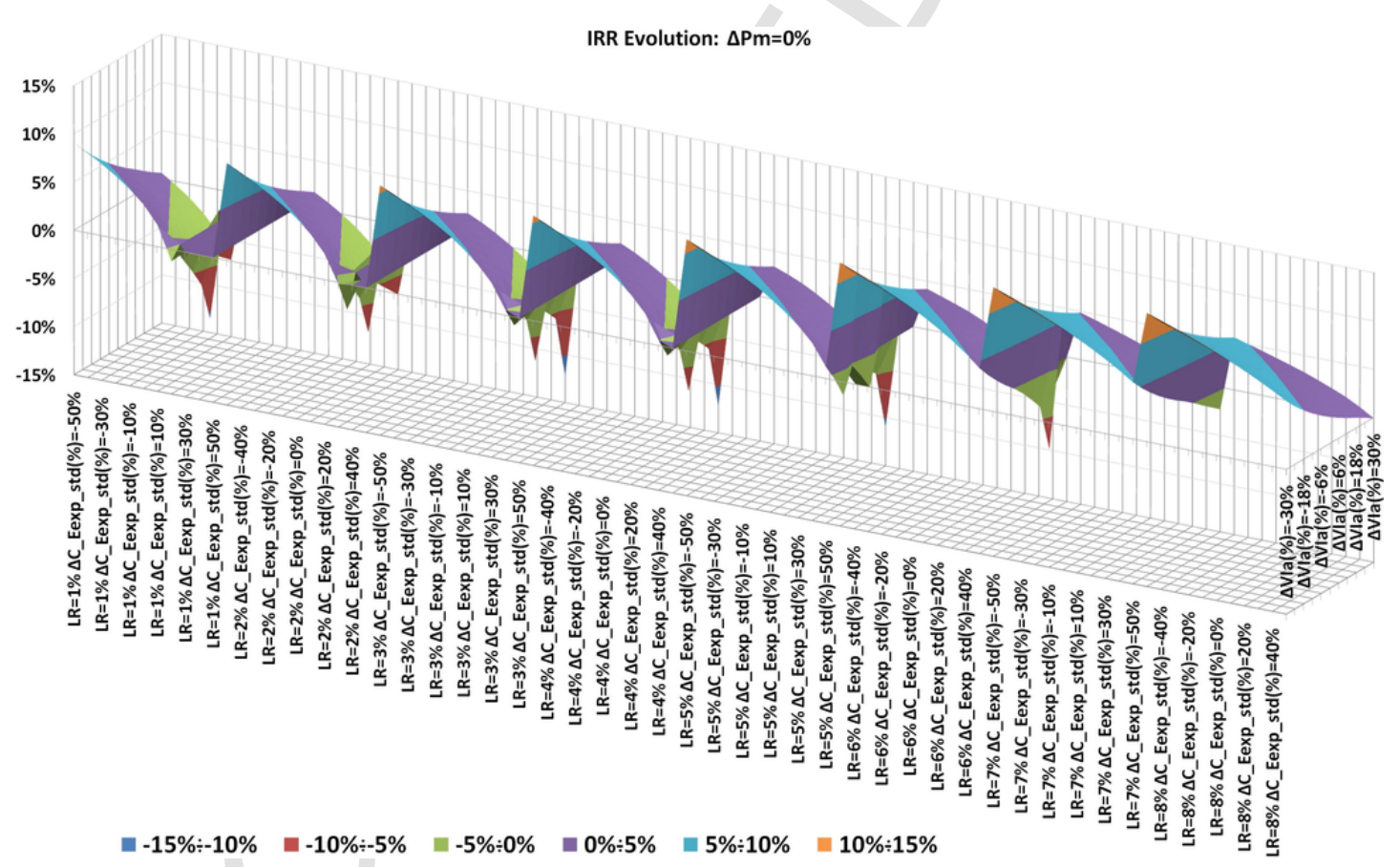

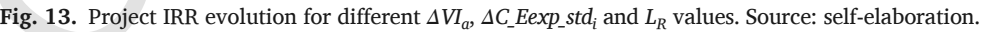

them in order to avoid bankruptcy, as the current revenues seem to be barely enough to face their operating and financial costs. In light of the favourable resolution of this last Award it would be reasonable to conclude that the still ongoing juridical battle between the Kingdom of Spain and the investors will continue in the near future.

\subsection{Final remarks regarding the modified model}

The undertaken research analysis on the $\mathrm{RD} 413 / 2014$ new regulatory framework applied to the CSPS in Spain has allowed to see how the complexity of this new scheme has introduced great difficulty and uncertainty when managing efficiently the CSP energy assets.
The model here provided has been proved to be useful to analyse the wide range of plausible scenarios (taking into account the evolution of the parameters either in its physical, economic or regulatory conception) related to the efficient management of the CSP energy assets in Spain. In this regard, the outputs of the model were selected taking into accounts their relevance and effects. According to the SCSPS, one of the most relevant problems that the sector itself has suffered has been the liquidity problems and the decrease of their legitimate expectations. Consequently, the chosen outputs of the model were the treasury, the IRR and the NPV as a clear and objective element able to highlight the evolution. As a result, it is worthy to stress that this research work has a clear and real application on the most spread CSP fa- 


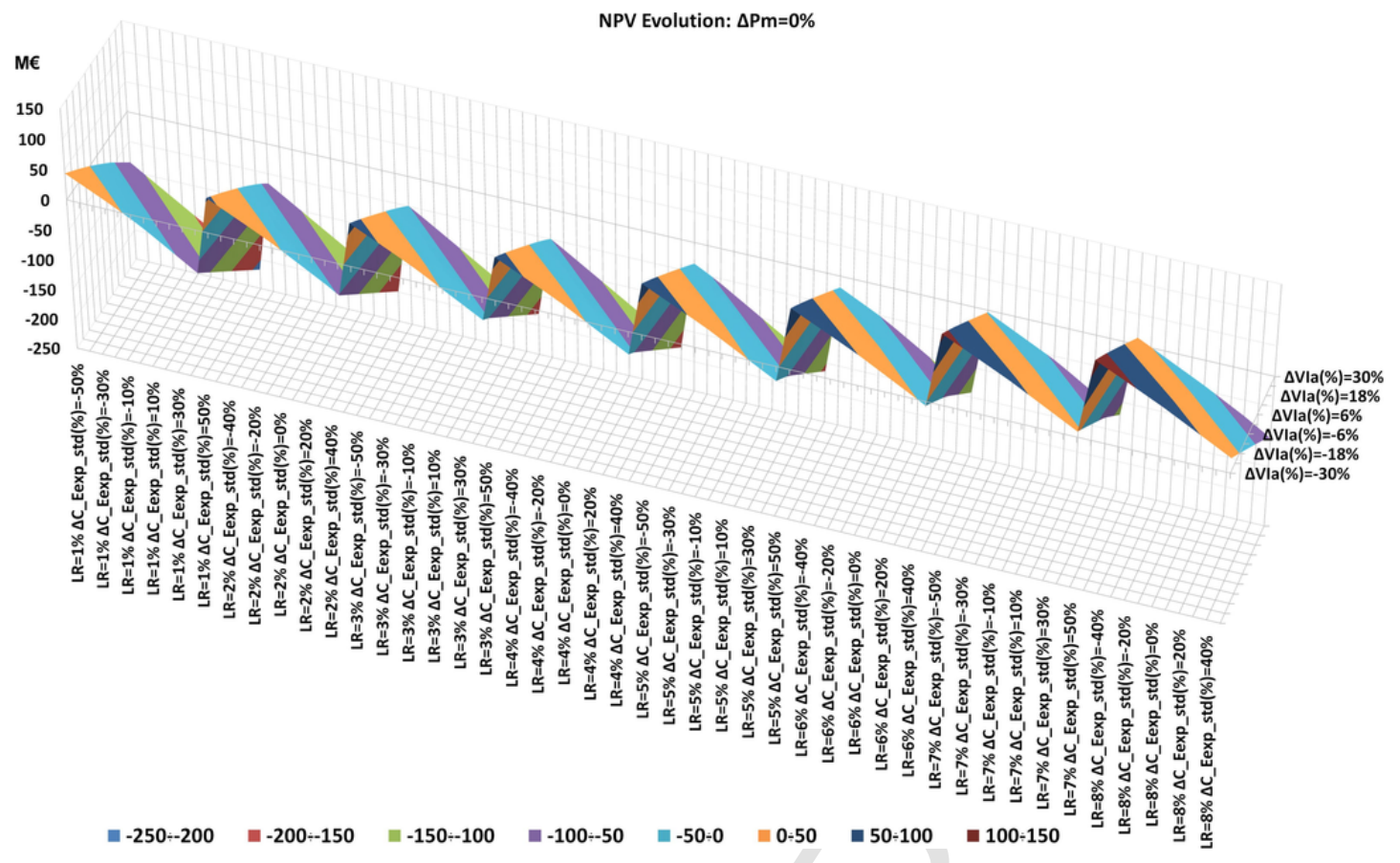

Fig. 14. Project NPV evolution for different $\Delta V I_{a}, \Delta C_{-} E \operatorname{Exp}_{-} s t d_{i}$ and $L_{R}$ values. Source: self-elaboration.

Table 10

Range of values of the parameters for the determination of the impact of the physical parameters.

Source: Self-elaboration

\begin{tabular}{lll}
\hline \multicolumn{2}{l}{ Impact of the physical parameters analysis } & \\
\hline Parameter & Range & Incremental step \\
\hline$\Delta V I_{a}(\%)$ & Treasury: $0 \%$ & - Treasury: - \\
& NPV, IRR: $[-30,30] \%$ & NPV, IRR: $6 \%$ \\
$\Delta N h_{-} s t d_{i}(\%)$ & {$[-30,30] \%$} & - Treasury: $5 \%$ \\
$\Delta C \_E \exp _{-} s t d_{i}(\%)$ & Treasury: $0 \%$ & NPV, IRR: $6 \%$ \\
$\Delta$ Pmf $_{i}(\%)$ & NPV, IRR: $[-50,50] \%$ & - Treasury: - \\
$\Delta t_{j}(\%)$ & $0 \%$ & NPV, IRR: $10 \%$ \\
$t_{j}=S B_{j}(\%)$ & $0 \%$ & - \\
$E q u i t y(\%)$ & $4 \%$ & - \\
Int_Rate $(\%)$ & $25 \%$ & - \\
$L_{R}(\%)$ & $5 \%$ & - \\
\hline
\end{tabular}

cilities in Spain, i.e., the parabolic trough without storage or with storage less than two hours. Namely, by means of this work, the managers of these premises will have a clear insight of the effects of the evolution of the system parameters on the economic results of these facilities (IRR, NPV, treasury, etc.), what will be certainly useful in order to take the right decisions in the management of these facilities.

Nevertheless, the study here conducted might be also helpful for the emerging CSP markets. Emerging markets like Chile, in Latin America, which is a leader in terms of installed CSP capacity with $110 \mathrm{MW}$ under construction. Or in Africa, where Morocco has by $20170.5 \mathrm{GW}$ of installed CSP capacity, or South Africa, which is expected to have the same figures at the end of 2019. But especially in Asia, where China with $1.4 \mathrm{GW}$ is expected to have the highest growth in terms of installed CSP capacity at the end of 2018 [100]. Although for these emerging CSP markets some studies have been conducted in the recent years, such as those focused in Chile [115-117] or China [118-121], the analysis of the Spanish case and its lessons learned here provided, as it goes beyond the traditional assessment based on the LCOE, clearly complement the economic assessment undertaken in these studies (even it might be a valuable tool for the optimized dispatch of this technology [122]). In fact, the capacity of modelling according to the regulatory scheme the characteristics of the economic framework that determines the total amount of the CSP revenues is one of the remarkable novelties of this work.

\section{Conclusions}

The article has analysed the RD 413/2014 new regulatory reform for RES in Spain and its great impact on the economic results of the SCSPS energy assets. This new regulatory framework has its inner conception based on an "Ex-post" assignment of what is supposed to be the most representative physical and economic parameters of an hypothetical "efficient and well managed plant". These standard values assigned to the regulatory parameters were retrospectively applied to existing CSPP, which made their investment decisions based on the previous RD $661 / 2007$ framework.

A new mathematical model intended to determine the impact of the $\mathrm{RD} 413 / 2014$ on the income statement of the CSPP has been described and justified. It has proved to be a useful tool to quantify the effects of the deviations of the actual parameters characterizing the CSPP from their standard values regulatory set.

Specifically, the model was applied to a case study of one of the most representative facilities of the SCSPS. The results have demonstrated that even "efficient and well managed plants" might see their liquidity, IRR and NPV seriously affected depending on the evolution of the financial regulatory parameters.

The results derived from the developed model have been confronted with the information published in the most recent arbitral Award involving the SCSPS. The comparison corroborated the results render by the developed model when analysing the impact of the parameters deviations of the energy asset from their standard values set by the regulations.

The presented model and its application to the representative case study here analysed might help to understand more clearly the impact of the regulatory parameters on the income statement of these energy assets, contributing to manage the uncertainty related to the RD 413/ 2014 new highly complex remuneration scheme. 
$\mathrm{M} €$

\section{Treasury $L R=2 \%$}

70

60

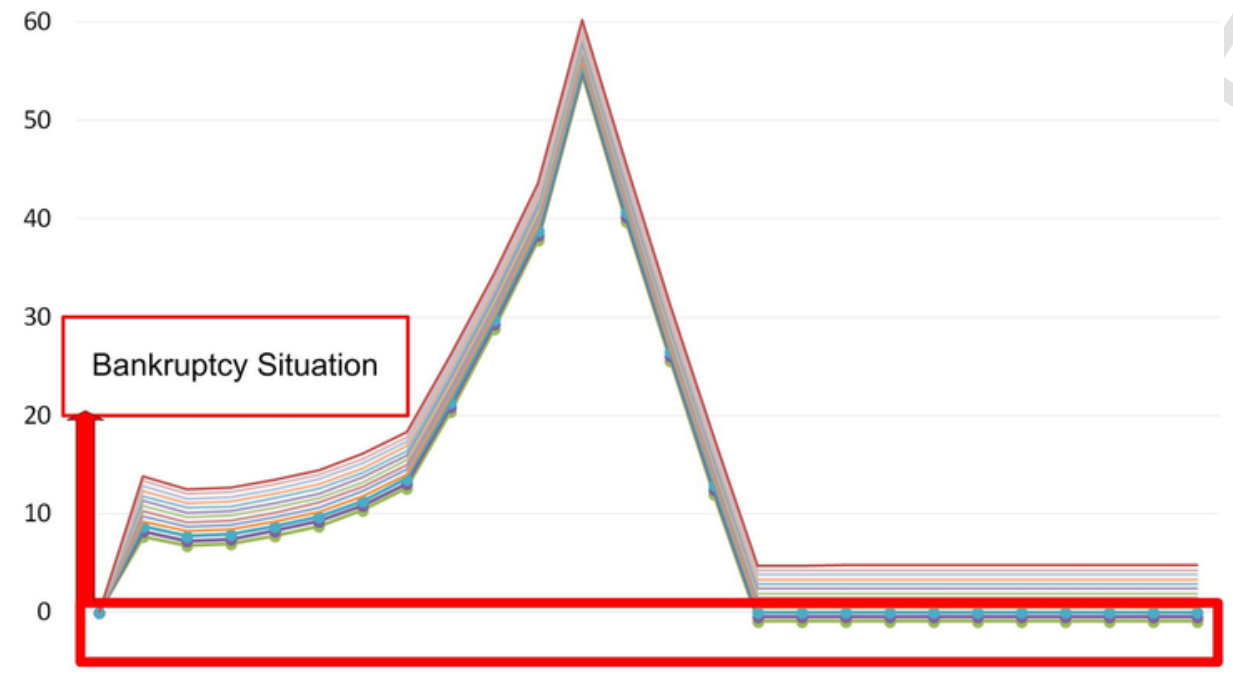

$-10$

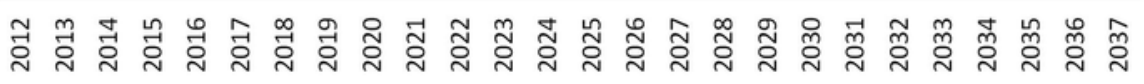

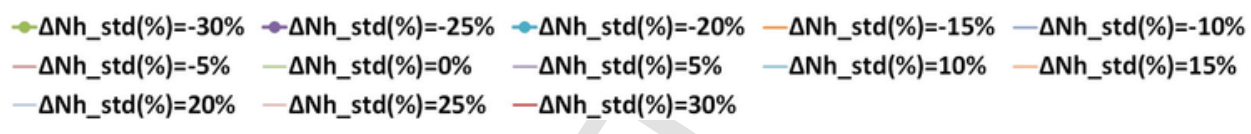

Fig. 15. Treasury evolution for different $\Delta N h_{-} s t d_{i}$ values and for $L_{R}=2 \%$.

\section{Acknowledgements}

The authors are especially grateful to all those persons and companies from the SCSPS who (confidentially and anonymously) have con- tributed to a better understanding of the CSPP reality in Spain. This work has been partially supported by the research project ENE2015-64087-C2-1-R (MINECO/FEDER). 

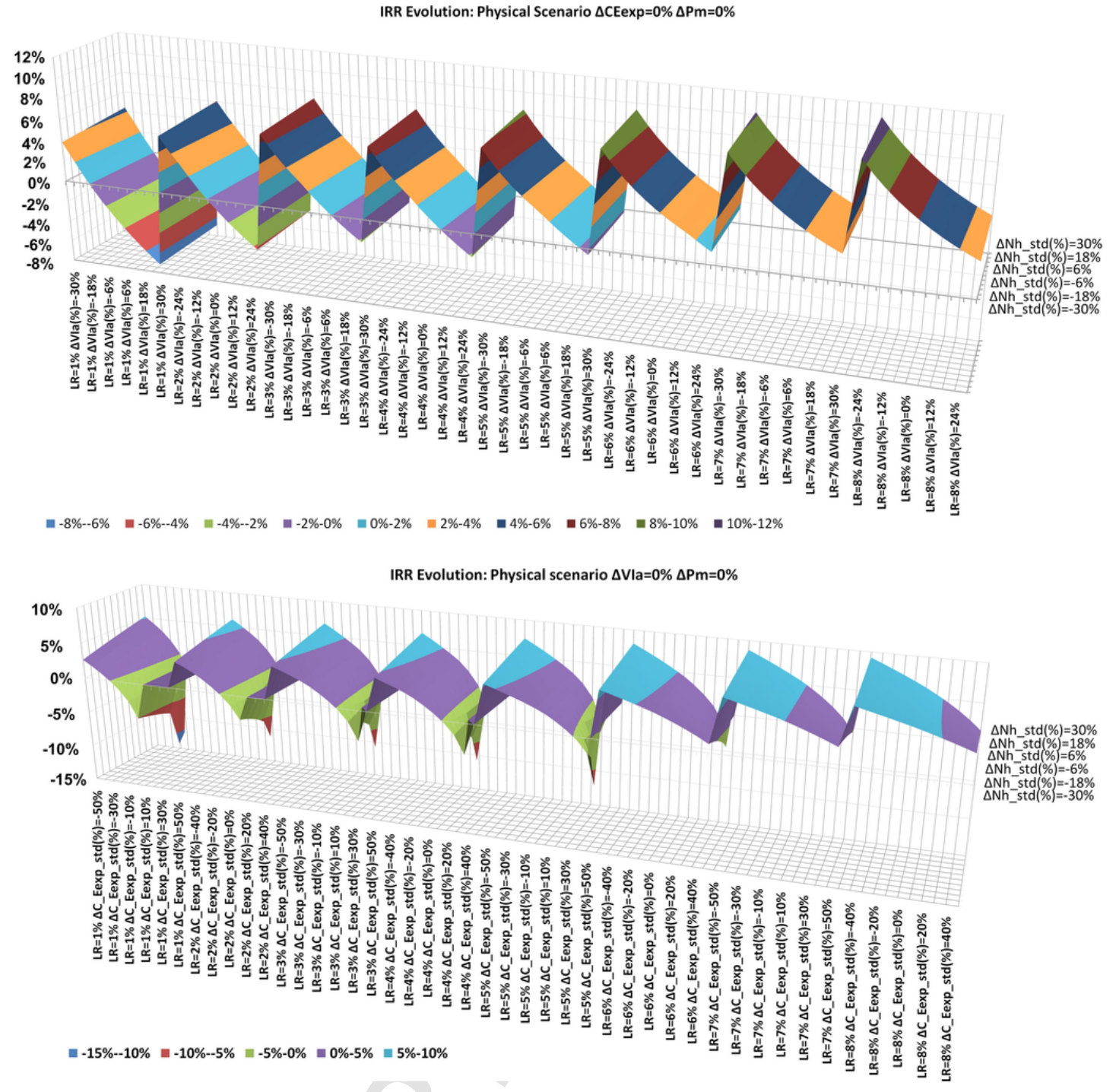

Fig. 16. Project IRR evolution for different $L_{R}, \Delta N h_{-} s t d_{i}$ and $\Delta V I_{a}$ values (upper subplot) and for different $L_{R}, \Delta N h_{-} s t d_{i}$ and $\Delta C_{-} E e x p \_s t d_{i}$ (lower subplot). Source: self-elaboration. 

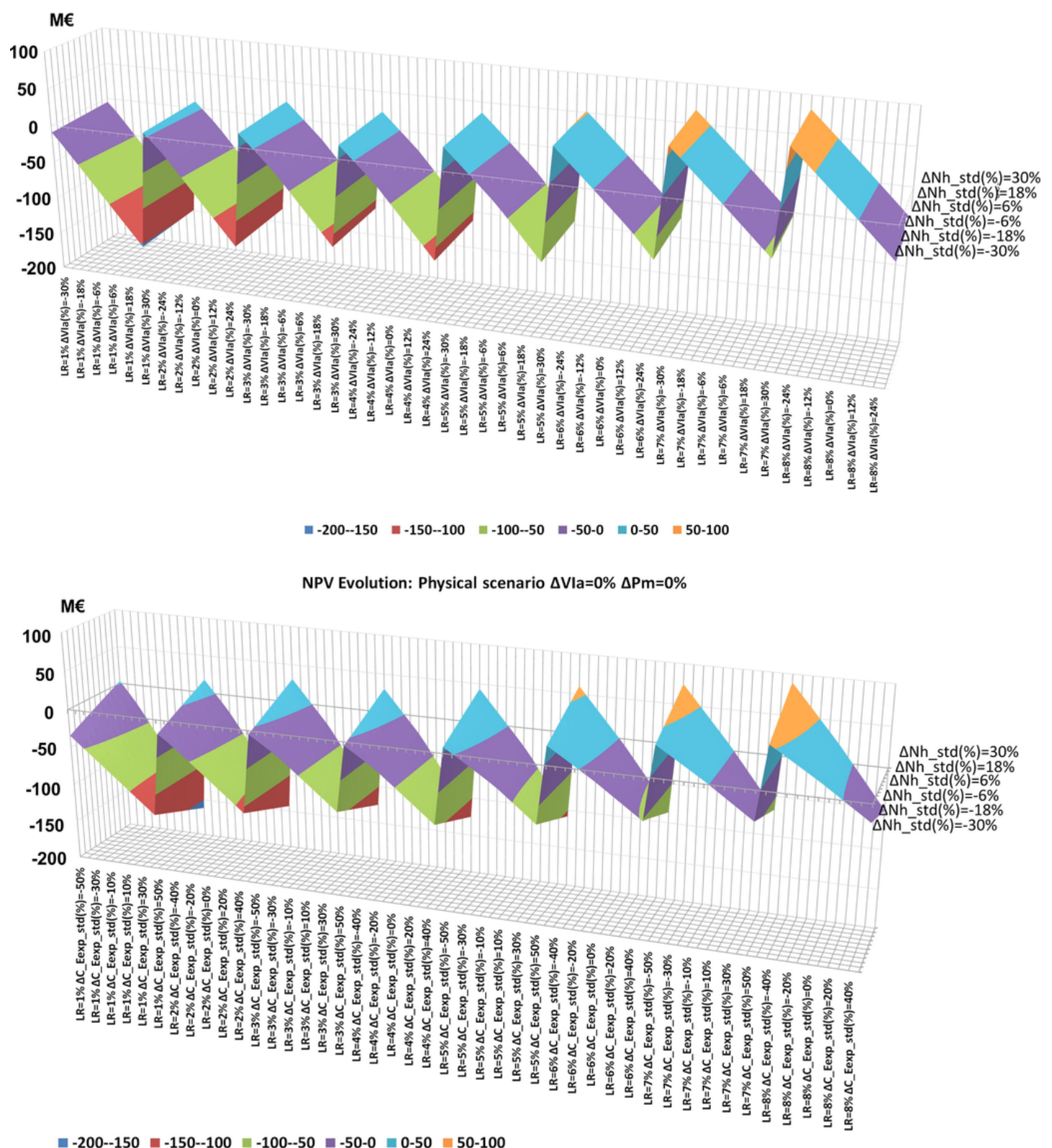

Fig. 17. Project NPV evolution for different $L_{R}, \Delta N h_{-} s t d_{i}$ and $\Delta V I_{a}$ values (upper subplot) and for different $L_{R}, \Delta N h_{-} s t d_{i}$ and $\Delta C_{-} E \operatorname{Exp} s t d_{i}$ (lower subplot). Source: self-elaboration.

\section{References}

[1] I. Rodríguez, C.D. Pérez-Segarra, O. Lehmkuhl, A. Oliva, Modular object-oriented methodology for the resolution of molten salt storage tanks for CSP plants, Appl Energy 109 (2013) 402-414, https://doi.org/10.1016/j.apenergy.2012.11.008.

[2] C. Pagkoura, G. Karagiannakis, A. Zygogianni, S. Lorentzou, M. Kostoglou, A.G. Konstandopoulos, et al., Cobalt oxide based structured bodies as redox thermochemical heat storage medium for future CSP plants, Sol Energy 108 (2014) 146-163, https://doi.org/10.1016/j.solener.2014.06.034.

[3] A.G. Fernández, S. Ushak, H. Galleguillos, F.J. Pérez, Development of new molten salts with LiNO3 and $\mathrm{Ca}(\mathrm{NO} 3) 2$ for energy storage in CSP plants, Appl Energy 119 (2014) 131-140, https://doi.org/10.1016/j.apenergy.2013.12.061.

[4] P.A. Galione, C.D. Pérez-Segarra, I. Rodríguez, A. Oliva, J. Rigola, Multi-layered solid-PCM thermocline thermal storage concept for CSP plants. Numerical analysis and perspectives, Appl Energy 142 (2015) 337-351, https://doi.org/10.1016/ j.apenergy.2014.12.084.

[5] S. Sau, N. Corsaro, T. Crescenzi, C. D’Ottavi, R. Liberatore, S. Licoccia, et al., Techno-economic comparison between CSP plants presenting two different heat transfer fluids, Appl Energy 168 (2016) 96-109, https://doi.org/10.1016/j. apenergy.2016.01.066.
[6] S. Guillot, A. Faik, A. Rakhmatullin, J. Lambert, E. Veron, P. Echegut, et al., Corrosion effects between molten salts and thermal storage material for concentrated solar power plants, Appl Energy 94 (2012) 174-181, https://doi.org/10.1016/j. apenergy.2011.12.057.

[7] T. Kim, D.M. France, W. Yu, W. Zhao, D. Singh, Heat transfer analysis of a latent heat thermal energy storage system using graphite foam for concentrated solar power, Sol Energy 103 (2014) 438-447, https://doi.org/10.1016/j.solener.2014. 02.038 .

[8] C. Corgnale, B. Hardy, T. Motyka, R. Zidan, J. Teprovich, B. Peters, Screening analysis of metal hydride based thermal energy storage systems for concentrating solar power plants, Renew Sustain Energy Rev (2014) https://doi.org/10.1016/j. rser.2014.07.049.

[9] M. Paskevicius, D.A. Sheppard, K. Williamson, C.E. Buckley, Metal hydride thermal heat storage prototype for concentrating solar thermal power, Energy 88 (2015) 469-477, https://doi.org/10.1016/j.energy.2015.05.068.

[10] S. Cingarapu, D. Singh, E.V. Timofeeva, M.R. Moravek, Use of encapsulated zinc particles in a eutectic chloride salt to enhance thermal energy storage capacity for concentrated solar power, Renew Energy 80 (2015) 508-516, https://doi.org/10. 1016/j.renene.2015.02.026.

[11] M. Liu, N.H. Steven Tay, S. Bell, M. Belusko, R. Jacob, G. Will, et al., Review on concentrating solar power plants and new developments in high temperature thermal energy storage technologies, Renew Sustain Energy Rev (2016) https:// doi.org/10.1016/j.rser.2015.09.026. 
[12] F. Zaversky, J. García-Barberena, M. Sánchez, D. Astrain, Transient molten salt two-tank thermal storage modeling for CSP performance simulations, Sol Energy 93 (2013) 294-311, https://doi.org/10.1016/j.solener.2013.02.034.

[13] A. Bruch, J.F. Fourmigué, R. Couturier, Experimental and numerical investigation of a pilot-scale thermal oil packed bed thermal storage system for CSP power plant, Sol Energy 105 (2014) 116-125, https://doi.org/10.1016/j.solener.2014. 03.019.

[14] E. Casati, F. Casella, P. Colonna, Design of CSP plants with optimally operated thermal storage, Sol Energy 116 (2015) 371-387, https://doi.org/10.1016/j. solener.2015.03.048.

[15] P.A. Galione, C.D. Pérez-Segarra, I. Rodríguez, S. Torras, J. Rigola, Multi-layered solid-PCM thermocline thermal storage for CSP. Numerical evaluation of its application in a 50MWe plant, Sol Energy 119 (2015) 134-150, https://doi.org/10. 1016/j.solener.2015.06.029.

[16] C. Parrado, A. Marzo, E. Fuentealba, A.G. Fernández, 2050 LCOE improvement using new molten salts for thermal energy storage in CSP plants, Renew Sustain Energy Revi (2016) https://doi.org/10.1016/j.rser.2015.12.148.

[17] X. Ju, C. Xu, G. Wei, X. Du, Y. Yang, A novel hybrid storage system integrating a packed-bed thermocline tank and a two-tank storage system for concentrating solar power (CSP) plants, Appl Therm Eng 92 (2016) 24-31, https://doi.org/10. 1016/j.applthermaleng.2015.09.083.

[18] C.W. Robak, T.L. Bergman, A. Faghri, Economic evaluation of latent heat therma energy storage using embedded thermosyphons for concentrating solar power applications, Sol Energy 85 (2011) 2461-2473, https://doi.org/10.1016/j.solener. 2011.07.006.

[19] F. Cavallaro, Fuzzy TOPSIS approach for assessing thermal-energy storage in con centrated solar power (CSP) systems, Appl Energy 87 (2010) 496-503, https:// doi.org/10.1016/j.apenergy.2009.07.009.

[20] R. Adinberg, Simulation analysis of thermal storage for concentrating solar power, Appl Therm Eng 31 (2011) 3588-3594, https://doi.org/10.1016/j. applthermaleng.2011.07.025.

[21] K. Nithyanandam, R. Pitchumani, Computational studies on a latent thermal energy storage system with integral heat pipes for concentrating solar power, Appl Energy 103 (2013) 400-415, https://doi.org/10.1016/j.apenergy.2012.09.056.

[22] G. Zanganeh, A. Pedretti, S. Zavattoni, M. Barbato, A. Steinfeld, Packed-bed ther mal storage for concentrated solar power - Pilot-scale demonstration and industrial-scale design, Sol Energy 86 (2012) 3084-3098, https://doi.org/10.1016/j . solener.2012.07.019.

[23] K. Nithyanandam, R. Pitchumani, Cost and performance analysis of concentrating solar power systems with integrated latent thermal energy storage, Energy 64 (2014) 793-810, https://doi.org/10.1016/j.energy.2013.10.095.

[24] F. Zaversky, M. Sánchez, D. Astrain, Object-oriented modeling for the transient response simulation of multi-pass shell-and-tube heat exchangers as applied in active indirect thermal energy storage systems for concentrated solar power, Energy 65 (2014) 647-664, https://doi.org/10.1016/j.energy.2013.11.070.

[25] E.G. Jung, J.H. Boo, Thermal analytical model of latent thermal storage with hea pipe heat exchanger for concentrated solar power, Sol Energy 102 (2014) 318-332, https://doi.org/10.1016/j.solener.2013.11.008.

[26] A. Modi, C.D. Pérez-Segarra, Thermocline thermal storage systems for conce trated solar power plants: One-dimensional numerical model and comparative analysis, Sol Energy 100 (2014) 84-93, https://doi.org/10.1016/j.solener.2013. 11.033 .

[27] B. Xu, P. Li, C. Chan, E. Tumilowicz, General volume sizing strategy for thermal storage system using phase change material for concentrated solar thermal powe plant, Appl Energy 140 (2015) 256-268, https://doi.org/10.1016/j.apenergy. 2014.11.046.

[28] J.-F. Hoffmann, T. Fasquelle, V. Goetz, X. Py, A thermocline thermal energy storage system with filler materials for concentrated solar power plants: Experimenta data and numerical model sensitivity to different experimental tank scales, Appl Therm Eng 100 (2016) 753-761, https://doi.org/10.1016/j.applthermaleng. 2016.01.110.

[29] S. Almsater, W. Saman, F. Bruno, Performance enhancement of high temperature latent heat thermal storage systems using heat pipes with and without fins for concentrating solar thermal power plants, Renew Energy 89 (2016) 36-50, https: //doi.org/10.1016/j.renene.2015.11.068.

[30] Z. Liao, A. Faghri, Thermal analysis of a heat pipe solar central receiver for concentrated solar power tower, Appl Therm Eng 102 (2016) 952-960, https://doi. org/10.1016/j.applthermaleng.2016.04.043.

[31] M.J. Vasallo, J.M. Bravo, A novel two-model based approach for optimal scheduling in CSP plants, Sol Energy 126 (2016) 73-92, https://doi.org/10.1016/j. solener.2015.12.041.

[32] M.J. Vasallo, J.M. Bravo, A MPC approach for optimal generation scheduling in CSP plants, Appl Energy 165 (2016) 357-370, https://doi.org/10.1016/j. apenergy.2015.12.092.

[33] H.M.I. Pousinho, J. Esteves, V.M.F. Mendes, M. Collares-Pereira, C. Pereira Cabrita, Bilevel approach to wind-CSP day-ahead scheduling with spinning reserve under controllable degree of trust, Renew Energy 85 (2016) 917-927, https: //doi.org/10.1016/j.renene.2015.07.022.

[34] S. Kuravi, J. Trahan, D.Y. Goswami, M.M. Rahman, E.K. Stefanakos, Thermal energy storage technologies and systems for concentrating solar power plants, Prog Energy Combust Sci (2013) https://doi.org/10.1016/j.pecs.2013.02.001.

[35] S.J. Wagner, E.S. Rubin, Economic implications of thermal energy storage for concentrated solar thermal power, Renew Energy 61 (2014) 81-95, https://doi. org $/ 10.1016 /$ j.renene.2012.08.013.

[36] B. Xu, P. Li, C. Chan, Application of phase change materials for thermal energy storage in concentrated solar thermal power plants: A review to recent developments, Appl Energy (2015) https://doi.org/10.1016/j.apenergy.2015.09.016.
[37] D. Cocco, F. Serra, Performance comparison of two-tank direct and thermocline thermal energy storage systems for $1 \mathrm{MWe}$ class concentrating solar power plants, Energy 81 (2015) 526-536, https://doi.org/10.1016/j.energy.2014.12.067.

[38] Q. Mao, Recent developments in geometrical configurations of thermal energy storage for concentrating solar power plant, Renew Sustain Energy Rev (2016) https://doi.org/10.1016/j.rser.2015.12.355.

[39] F. De Luca, V. Ferraro, V. Marinelli, On the performance of CSP oil-cooled plants, with and without heat storage in tanks of molten salts, Energy 83 (2015) 230-239, https://doi.org/10.1016/j.energy.2015.02.017.

[40] I. Bendato, L. Cassettari, M. Mosca, R. Mosca, Stochastic techno-economic assessment based on Monte Carlo simulation and the Response Surface Methodology: The case of an innovative linear Fresnel CSP (concentrated solar power) system, Energy 101 (2016) 309-324, https://doi.org/10.1016/j.energy.2016.02.048.

[41] C. Kost, M. Engelken, T. Schlegl, Value generation of future CSP projects in North Africa, Energy Policy 46 (2012) 88-99, https://doi.org/10.1016/j.enpol.2012.03. 034.

[42] N. Corral, N. Anrique, D. Fernandes, C. Parrado, G. Cáceres, Power, placement and LEC evaluation to install CSP plants in northern Chile, Renew Sustain Energy Rev 16 (2012) 6678-6685, https://doi.org/10.1016/j.rser.2012.09.006.

[43] J.H. Peterseim, U. Hellwig, A. Tadros, S. White, Hybridisation optimization of concentrating solar thermal and biomass power generation facilities, Sol Energy 99 (2014) 203-214, https://doi.org/10.1016/j.solener.2013.10.041.

[44] Y. Tanaka, S. Mesfun, K. Umeki, A. Toffolo, Y. Tamaura, K. Yoshikawa, Thermodynamic performance of a hybrid power generation system using biomass gasification and concentrated solar thermal processes, Appl Energy 160 (2015) 664-672, https://doi.org/10.1016/j.apenergy.2015.05.084

[45] R. Soria, J. Portugal-Pereira, A. Szklo, R. Milani, R. Schaeffer, Hybrid concentrated solar power (CSP)-biomass plants in a semiarid region: A strategy for CSP deployment in Brazil, Energy Policy 86 (2015) 57-72, https://doi.org/10.1016/j. enpol.2015.06.028.

[46] G. San Miguel, B. Corona, Hybridizing concentrated solar power (CSP) with biogas and biomethane as an alternative to natural gas: Analysis of environmental performance using LCA, Renew Energy 66 (2014) 580-587, https://doi.org/10. 1016/j.renene.2013.12.023.

[47] E.M.A. Mokheimer, Y.N. Dabwan, M.A. Habib, Optimal integration of solar energy with fossil fuel gas turbine cogeneration plants using three different CSP technologies in Saudi Arabia, Appl Energy 185 (2017) 1268-1280, https://doi. org/10.1016/j.apenergy.2015.12.029.

[48] M.J. Emes, M. Arjomandi, G.J. Nathan, Effect of heliostat design wind speed on the levelised cost of electricity from concentrating solar thermal power tower plants, Sol Energy 115 (2015) 441-451, https://doi.org/10.1016/j.solener.2015. 02.047 .

[49] N.B. Desai, S. Bandyopadhyay, Optimization of concentrating solar therma power plant based on parabolic trough collector, J Clean Prod 89 (2015) 262-271, https://doi.org/10.1016/j.jclepro.2014.10.097.

[50] N.B. Desai, S.B. Kedare, S. Bandyopadhyay, Optimization of design radiation for concentrating solar thermal power plants without storage, Sol Energy 107 (2014) 98-112, https://doi.org/10.1016/j.solener.2014.05.046.

[51] A. Fleming, C. Folsom, H. Ban, Z. Ma, A general method to analyze the thermal performance of multi-cavity concentrating solar power receivers, Sol Energy 150 (2015) 608-618, https://doi.org/10.1016/j.solener.2015.08.007.

[52] V.S. Reddy, S.C. Kaushik, S.K. Tyagi, Exergetic analysis and performance evaluation of parabolic trough concentrating solar thermal power plant (PTCSTPP), Energy 39 (2012) 258-273, https://doi.org/10.1016/j.energy.2012.01.023.

[53] S. Bouaddi, A. Ihlal, A. Fernández-García, Soiled CSP solar reflectors modeling using dynamic linear models, Sol Energy 122 (2015) 847-863, https://doi.org/10. 1016/j.solener.2015.09.044

[54] M. Karim, S. Naamane, E.L. El Amrani, I. Hassani, C. Delord, S. Belcadi, et al., Towards the prediction of CSP mirrors wear: Methodology of analysis of influencing parameters on the mirrors surface degradation: Application in two different sites in Morocco, Sol Energy 108 (2014) 41-50, https://doi.org/10.1016/j.solener. 2014.06.036.

[55] Y. Zhang, S.J. Smith, G.P. Kyle, P.W. Stackhouse, Modeling the potential for thermal concentrating solar power technologies, Energy Policy 38 (2010) 7884-7897, https://doi.org/10.1016/j.enpol.2010.09.008.

[56] L. Dawson, P. Schlyter, Less is more: Strategic scale site suitability for concentrated solar thermal power in Western Australia, Energy Policy 47 (2012) 91-101, https://doi.org/10.1016/j.enpol.2012.04.025.

[57] J. Chung-Ling Chien, N. Lior, Concentrating solar thermal power as a viable alternative in China's electricity supply, Energy Policy 39 (2011) 7622-7636, https:// doi.org/10.1016/j.enpol.2011.08.034.

[58] D. Malagueta, A. Szklo, R. Soria, R. Dutra, R. Schaeffer, Moreira Cesar Borba, et al., Potential and impacts of Concentrated Solar Power (CSP) integration in the Brazilian electric power system, Renew Energy 68 (2014) 223-235, https://doi org/10.1016/j.renene.2014.01.050.

[59] M. Balghouthi, S.E. Trabelsi, M. Ben Amara, A.B.H. Ali, A. Guizani, Potential of concentrating solar power (CSP) technology in Tunisia and the possibility of interconnection with Europe, Renew Sustain Energy Rev (2016) https://doi.org/10. 1016/j.rser.2015.12.052

[60] E.R. Shouman, N.M. Khattab, Future economic of concentrating solar power (CSP) for electricity generation in Egypt, Renew Sustain Energy Rev (2015) https: //doi.org/10.1016/j.rser.2014.08.067.

[61] F. Manenti, Z. Ravaghi-Ardebili, Dynamic simulation of concentrating solar power plant and two-tanks direct thermal energy storage, Energy 55 (2013) 89-97, https://doi.org/10.1016/j.energy.2013.02.001.

[62] P. Viebahn, Y. Lechon, F. Trieb, The potential role of concentrated solar power (CSP) in Africa and Europe-A dynamic assessment of technology development, cost development and life cycle inventories until 2050, Energy Policy 39 (2011) 4420-4430, https://doi.org/10.1016/j.enpol.2010.09.026. 
[63] K. Burlafinger, A. Vetter, C.J. Brabec, Maximizing concentrated solar power (CSP) plant overall efficiencies by using spectral selective absorbers at optimal operation temperatures, Sol Energy 120 (2015) 428-438, https://doi.org/10.1016/j. solener.2015.07.023.

[64] J. Polo, F.M. Téllez, C. Tapia, Comparative analysis of long-term solar resource and CSP production for bankability, Renew Energy 90 (2016) 38-45, https://doi. org/10.1016/j.renene.2015.12.057.

[65] J.F.P. Pitot de la Beaujardiere, H.C.R. Reuter, S.A. Klein, D.T. Reindl, Impact of HRSG characteristics on open volumetric receiver CSP plant performance, Sol Energy 127 (2016) 159-174, https://doi.org/10.1016/j.solener.2016.01.030.

[66] A. Boubault, C.K. Ho, A. Hall, T.N. Lambert, A. Ambrosini, Levelized cost of energy (LCOE) metric to characterize solar absorber coatings for the CSP industry, Renew Energy 85 (2016) 472-483, https://doi.org/10.1016/j.renene.2015.06. 059.

[67] E. Pihl, D. Kushnir, B. Sandén, F. Johnsson, Material constraints for concentrating solar thermal power, Energy 44 (2012) 944-954, https://doi.org/10.1016/j. energy.2012.04.057.

[68] L. Qoaider, A. Liqreina, Optimization of dry cooled parabolic trough (CSP) plants for the desert regions of the Middle East and North Africa (MENA), Sol Energy 122 (2015) 976-985, https://doi.org/10.1016/j.solener.2015.10.021.

[69] A. Liqreina, L. Qoaider, Dry cooling of concentrating solar power (CSP) plants, an economic competitive option for the desert regions of the MENA region, Sol Energy 103 (2014) 417-424, https://doi.org/10.1016/j.solener.2014.02.039.

[70] V. Quaschning, Technical and economical system comparison of photovoltaic and concentrating solar thermal power systems depending on annual global irradiation, Sol Energy 77 (2004) 171-178, https://doi.org/10.1016/j.solener.2004.04. 011.

[71] J. Lilliestam, J.M. Bielicki, A.G. Patt, Comparing carbon capture and storage (CCS) with concentrating solar power (CSP): Potentials, costs, risks, and barriers, Energy Policy 47 (2012) 447-455, https://doi.org/10.1016/j.enpol.2012.05.020

[72] V. Poghosyan, M.I. Hassan, Techno-economic assessment of substituting natural gas based heater with thermal energy storage system in parabolic trough concentrated solar power plant, Renew Energy 75 (2015) 152-164, https://doi.org/10. 1016/j.renene.2014.09.025

[73] J. Hernández-Moro, J.M. Martínez-Duart, CSP electricity cost evolution and grid parities based on the IEA roadmaps, Energy Policy 41 (2012) 184-192, https:// doi.org/10.1016/j.enpol.2011.10.032.

[74] J. Hernández-Moro, J.M. Martínez-Duart, Analytical model for solar PV and CSP electricity costs: Present LCOE values and their future evolution, Renew Sustain Energy Rev (2013) https://doi.org/10.1016/j.rser.2012.11.082.

[75] R. Domínguez, A.J. Conejo, M. Carrión, Operation of a fully renewable electric energy system with CSP plants, Appl Energy 119 (2014) 417-430, https://doi. org/10.1016/j.apenergy.2014.01.014.

[76] H.M.I. Pousinho, H. Silva, V.M.F. Mendes, M. Collares-Pereira, C. Pereira Cabrita Self-scheduling for energy and spinning reserve of wind/CSP plants by a MILP approach, Energy 78 (2014) 524-534, https://doi.org/10.1016/j.energy.2014.10. 039.

[77] B. Brand, A. Boudghene Stambouli, D. Zejli, The value of dispatchability of CSP plants in the electricity systems of Morocco and Algeria, Energy Policy 47 (2012) 321-331, https://doi.org/10.1016/j.enpol.2012.04.073.

[78] R. Mahia, R. De Arce, E. Medina, Assessing the future of a CSP industry in Morocco, Energy Policy 69 (2014) 586-597, https://doi.org/10.1016/j.enpol.2014. 02.024 .

[79] H. Elrefaei, A. Bida, M. Elsobky, M. Hallouda, Renewable energy market competence index part 2: Application to CSP technology, Renew Energy 53 (2013) 413-422, https://doi.org/10.1016/j.renene.2012.09.013.

[80] J. Usaola, Participation of CSP plants in the reserve markets: A new challenge for regulators, Energy Policy 49 (2012) 562-571, https://doi.org/10.1016/j.enpol. 2012.06.060.

[81] H. Martín, J. De La Hoz, G. Velasco, M. Castilla, J.L. García De Vicuña, Promotion of concentrating solar thermal power (CSP) in Spain: Performance analysis of the period 1998-2013, Renew Sustain Energy Rev 50 (2015) 1052-1068, https://doi. org/10.1016/j.rser.2015.05.062.

[82] Keith Williges, Johan Lilliestam, Anthony Patt, Making concentrated solar power competitive with coal: The costs of a European feed-in tariff, Energy Policy 38 (6) (2010) 3089-3097.

[83] M.S. Shahmohammadi, R. Mohd, S. Keyhanian, H.S. G, A decision support system for evaluating effects of Feed-in Tariff mechanism : Dynamic modeling of Malaysia 's electricity generation mix, Appl Energy 146 (2015) 217-229, https: //doi.org/10.1016/j.apenergy.2015.01.076.

[84] P. Behrens, J.F.D. Rodrigues, T. Brás, C. Silva, Environmental, economic, and social impacts of feed-in tariffs: A Portuguese perspective 2000-2010, Appl Energy 173 (2016) 309-319, https://doi.org/10.1016/j.apenergy.2016.04.044.

[85] R. Fagiani, J. Barquin, R. Hakvoort, Risk-based assessment of the cost-efficiency and the effectivity of renewable energy support schemes: Certificate markets versus feed-in tariffs, Energy Policy 55 (2013) 648-661, https://doi.org/10.1016/j. enpol.2012.12.066

[86] D. Zafirakis, K.J. Chalvatzis, G. Baiocchi, G. Daskalakis, Modelling of financial in centives for investments in energy storage systems that promote the large-scale integration of wind energy, Appl Energy 105 (2013) 138-154.

[87] Matthias Ritter, Lars Deckert, Site assessment, turbine selection, and local feed-in tariffs through the wind energy index, Appl Energy 185 (Part 2) (2017) 1087-1099, 1 January.

[88] J. Nordensvärd, F. Urban, The stuttering energy transition in Germany: Wind energy policy and feed-in tariff lock-in, Energy Policy 82 (2015) 156-165, https:// doi.org/10.1016/j.enpol.2015.03.009.

[89] M. Antonelli, U. Desideri, Do feed-in tariffs drive PV cost or viceversa?, Appl Energy 135 (2014) 721-729, https://doi.org/10.1016/j.apenergy.2014.06.059.
[90] Liang-Cheng Ye, João F.D. Rodrigues, Hai Xiang Lin, Analysis of feed-in tariff policies for solar photovoltaic in China 2011-2016, Appl Energy 203 (1) (October 2017) 496-505.

[91] G. Brusco, A. Burgio, D. Menniti, A. Pinnarelli, N. Sorrentino, The economic viability of a feed-in tariff scheme that solely rewards self-consumption to promote the use of integrated photovoltaic battery systems, Appl Energy 183 (2016) 1075-1085, https://doi.org/10.1016/j.apenergy.2016.09.004.

[92] C.W. Hsu, Using a system dynamics model to assess the effects of capital subsidies and feed-in tariffs on solar PV installations, Appl Energy 100 (2012) 205-217, https://doi.org/10.1016/j.apenergy.2012.02.039.

[93] R. Wand, F. Leuthold, Feed-in tariffs for photovoltaics: Learning by doing in Germany?, Appl Energy 88 (2011) 4387-4399, https://doi.org/10.1016/j.apenergy. 2011.05.015.

[94] M. Herrando, C.N. Markides, Hybrid PV and solar-thermal systems for domestic heat and power provision in the UK: Techno-economic considerations, Appl Energy 161 (2014) 512-532.

[95] B. Fais, M. Blesl, U. Fahl, A. Voß, Comparing different support schemes for renewable electricity in the scope of an energy systems analysis, Appl Energy 131 (2014) 479-489.

[96] D. Burtt, P. Dargusch, The cost-effectiveness of household photovoltaic systems in reducing greenhouse gas emissions in Australia: Linking subsidies with emission reductions, Appl Energy 148 (2015) 439-448.

[97] Y. Yamaguchi, K. Akai, J. Shen, N. Fujimura, Y. Shimoda, T. Saijo, Prediction of photovoltaic and solar water heater diffusion and evaluation of promotion policies on the basis of consumers' choices, Appl Energy 102 (2013) 1148-1159.

[98] Oh. Jeongyoon, Choongwan Koo, Taehoon Hong, Kwangbok Jeong Minhyun Lee, An economic impact analysis of residential progressive electricity tariffs in implementing the building-integrated photovoltaic blind using an advanced finite element model, Appl Energy 202 (15) (2017) 259-274, https://doi.org/10.1016/j. apenergy.2017.05.158.

[99] J. de la Hoz, H. Martín, J. Ballart, Ll. Monjo, Evaluating the approach to reduce the economic impact of grid connected PV systems on the Spanish electricity sector: performance analysis of the period 2010-2012, Appl Energy 121 (2014) 159-173.

[100] REN21. Renewables 2016. Global status report. 2016.: http://www.ren21.net/ wp-content/uploads/2016/06/GSR_2016_Full_Report.pdf. Last access on line, August 2017.

[101] Tirado JM. Renewable energy claims under the energy charter treaty: an overview. Transnational Dispute Management 2015, vol. 13, Issue 3.

[102] International Investments Agreements (IIA). Issues notes. Investor-state dispute settlement: review of developments in 2015. June 2016. Issue 2. http://unctad. org/en/PublicationsLibrary/webdiaepcb2016d4_en.pdf. Last access on line, August 2017.

[103] International Investments Agreements (IIA). Issues notes. Investor-state dispute settlement: review of developments in 2016. May 2017. Issue 1. http://unctad. org/en/PublicationsLibrary/diaepcb2017d1_en.pdf. Last access on line: August 2017.

[104] ICSID Case No. ARB/13/36. http://www.energycharter.org/fileadmin/ DocumentsMedia/Disputes/ISDSC-043en.pdf. Last access on line: August 2017.

[105] Solar Paces. http://www.solarpaces.org/images/articulos/pfmkfcfkgmgkeeak. png. Last access on line: August 2017.

[106] RDL9/2013, of 12 July. BOE no. 310, July 13, 2013. http://www.boe.es/diario boe/txt.php?id = BOE-A-2013-13645. Last access online, August 2017.

[107] RD 661/2007, of 25 May. BOE no. 126, May 26, 2007. https://www.boe.es/ buscar/act.php?id = BOE-A-2007-10556. Last access online, August 2017.

[108] RD 1578/2008, of 26 September. BOE no. 126, September 27, 2008. https:// www.boe.es/buscar/doc.php?id = BOE-A-2008-15595. Last access online, August 2017.

[109] Law 24/2013, of 26 December. BOE no. 167, December 27, 2013. http://www. boe.es/diario_boe/txt.php?id=BOE-A-2013-13645. Last access online, August 2017.

[110] RD 413/2014, of 6 June. BOE no. 140, June 8, 2014. http://www.boe.es/diario boe/txt.php?id= BOE-A-2014-6123. Last access online, August 2017.

[111] MO IET/1045/2014, of 16 June. BOE no. 150, June 20, 2014, http://www.boe. es/boe/dias/2014/06/20/ Last access online, August 2017.

[112] Plan de energías renovables en España 2005-2010. Ministerio de Industria, Turismo y Comercio. Instituto para la diversificación y ahorro de enegía, IDAE. August 2005.

[113] J. de la Hoz, H. Martín, J. Miret, M. Castilla, R. Guzman, Evaluating the 2014 retroactive regulatory framework applied to the grid connected PV systems in Spain, Appl Energy 170 (2016) 329-344, 15 May.

[114] El Confidencial, June 2017: https://www.elconfidencial.com/economia/ 2017-06-21/energias-renovables-gobierno-rentabilidad-interes-inversion_ 1402739/. Last access on line, August 2017.

[115] Carlos Valenzuela, Carlos Mata-Torres, José M. Cardemil, Rodrigo A. Escobar, CSP + PV hybrid solar plants for power and water cogeneration in northern Chile, Sol Energy 157 (15) (November 2017) 713-726.

[116] Allan R. Starke, José M. Cardemil, Rodrigo A. Escobar, Sergio Colle, Assessing the performance of hybrid CSP + PV plants in northern Chile, Sol Energy 138 (15) (November 2016) 88-97.

[117] C. Parrado, A. Girard, F. Simon, E. Fuentealba, 2050 LCOE (Levelized Cost of Energy) projection for a hybrid PV (photovoltaic)-CSP (concentrated solar power) plant in the Atacama Desert, Chile, Energy 94 (1) (January 2016) 422-430.

[118] John A. Mathews, Hu. Mei-Chih, Wu. Ching-Yan, Are the land and other resources required for total substitution of fossil fuel power systems impossibly large? Evidence from concentrating solar power and China, Renew Sustain Energy Rev 46 (June 2015) 275-281. 
[119] Zhen-Yu Zhao, Yu-Long Chen, John Douglas Thomson, Levelized cost of energy modeling for concentrated solar power projects: A China study, Energy 120 (1) (2017) 117-127.

[120] Zhao Zhu, Da. Zhang, Peggy Mischke, Xiliang Zhang, Electricity generation costs of concentrated solar power technologies in China based on operational plants, Energy 89 (2015) 65-74.
[121] Luiz Enrique Vieira, Alina de Souza, Mikhailovna Gilmanova Cavalcante, Concentrated solar power deployment in emerging economies: The cases of China and Brazil, Renew Sustain Energy Rev 72 (2017) 1094-1103.

[122] Michael J. Wagner, Alexandra M. Newman, William T. Hamilton, Robert J. Braun, Optimized dispatch in a first-principles concentrating solar power production model, Appl Energy 203 (1) (2017) 959-971. 